\title{
Local and remote forcing of currents and temperature in the central Southern California Bight
}

\author{
B. M. Hickey \\ School of Oceanography, University of Washington, Seattle, Washington, USA
}

E. L. Dobbins

Joint Institute for the Study of the Atmosphere and Ocean, University of Washington, Seattle, Washington, USA

S. E. Allen

Department of Earth and Ocean Sciences, University of British Columbia, Vancouver, British Columbia, Canada

Received 31 March 2000; revised 17 December 2001; accepted 18 March 2002; published 15 March 2003.

[1] A comprehensive study of the central Southern California Bight shows that subtidal currents are dominated by relatively long time scales (10-25 days), large alongshore scales, and significant offshore and upward phase propagation. A one-dimensional model shows that observed fluctuating, poleward propagating (speeds $140-260 \mathrm{~cm} \mathrm{~s}^{-1}$ ) alongshore pressure gradient disturbances account for a much larger fraction of the alongshore velocity variance than local wind stress (at least $40 \%$ in both seasons) and have the longer periods of the dominant currents. With the addition of local wind stress, about half the velocity variance can be accounted for, and overall, about 5\% more variance in spring than in summer. Results are consistent with generation of disturbances by remote wind stress several hundred kilometers equatorward of the bight and alongcoast propagation as low-mode coastally trapped waves. The large-scale remote forcing is also responsible for much of the velocity variance on the adjacent shelf, the semienclosed Santa Monica Bay. A nonlinear, three-dimensional model shows that water is pushed into the bay initially as part of a throughflow, later becoming an eddy that gradually fills the bay, producing counterflow on its shoreward side. On the shelf, local alongshore wind stress accounts for only $25 \%$ of the velocity variance in spring and none in summer. The largescale disturbances also produce significant temperature fluctuations throughout the region, via lateral advection of the mean alongshore temperature gradient. Local wind-driven coastal upwelling is responsible for temperature fluctuations on the inner shelf during several 2-4 day events in spring, but only very near the coastal wall. INDEX TERMS: 4219 Oceanography: General: Continental shelf processes; 4223 Oceanography: General: Descriptive and regional oceanography; 4512 Oceanography: Physical: Currents; 4516 Oceanography: Physical: Eastern boundary currents; KEYWORDS: coastal trapped waves, alongshore pressure gradient, southern California currents, water temperature, coastal circulation, remote forcing

Citation: Hickey, B. M., E. L. Dobbins, and S. E. Allen, Local and remote forcing of currents and temperature in the central Southern California Bight, J. Geophys. Res., 108(C3), 3081, doi:10.1029/2000JC000313, 2003.

\section{Introduction}

[2] This paper addresses forcing mechanisms for eventscale circulation and water temperature variability in the central Southern California Bight (henceforth "SC Bight"). The SC Bight is the region of the North American west coast where the coastline bends almost 90 degrees toward the coast, indenting the relatively straight coastline to the north and south for about $300 \mathrm{~km}$ (Figure 1). The bight is punctuated by a series of complex topographic features such as islands, basins and ridges that exert strong control on circulation patterns at every depth. In the mean, the ocean-

Copyright 2003 by the American Geophysical Union. 0148-0227/03/2000JC000313\$09.00 ography of the bight is governed by seasonal patterns in the California Current system (see schematic circulation in Figure 1) [Hickey, 1979, 1998; Lynn and Simpson, 1987, 1990; Bray et al., 1997]. The California Current flows equatorward offshore of the bight and is most fully developed in late summer and early fall. South of Point Conception and inshore of the equatorward flowing California Current, the Southern California Countercurrent flows poleward through the bight. The Countercurrent is strongest in summer and early fall, and weakest or even nonexistent in spring. Beneath the sea surface $(\sim 100-200 \mathrm{~m}$ core depth) the poleward flowing California Undercurrent is the dominant feature of circulation in the bight. Seasonal water properties are controlled by the seasonal currents; colder California Current water is advected southward from Point 

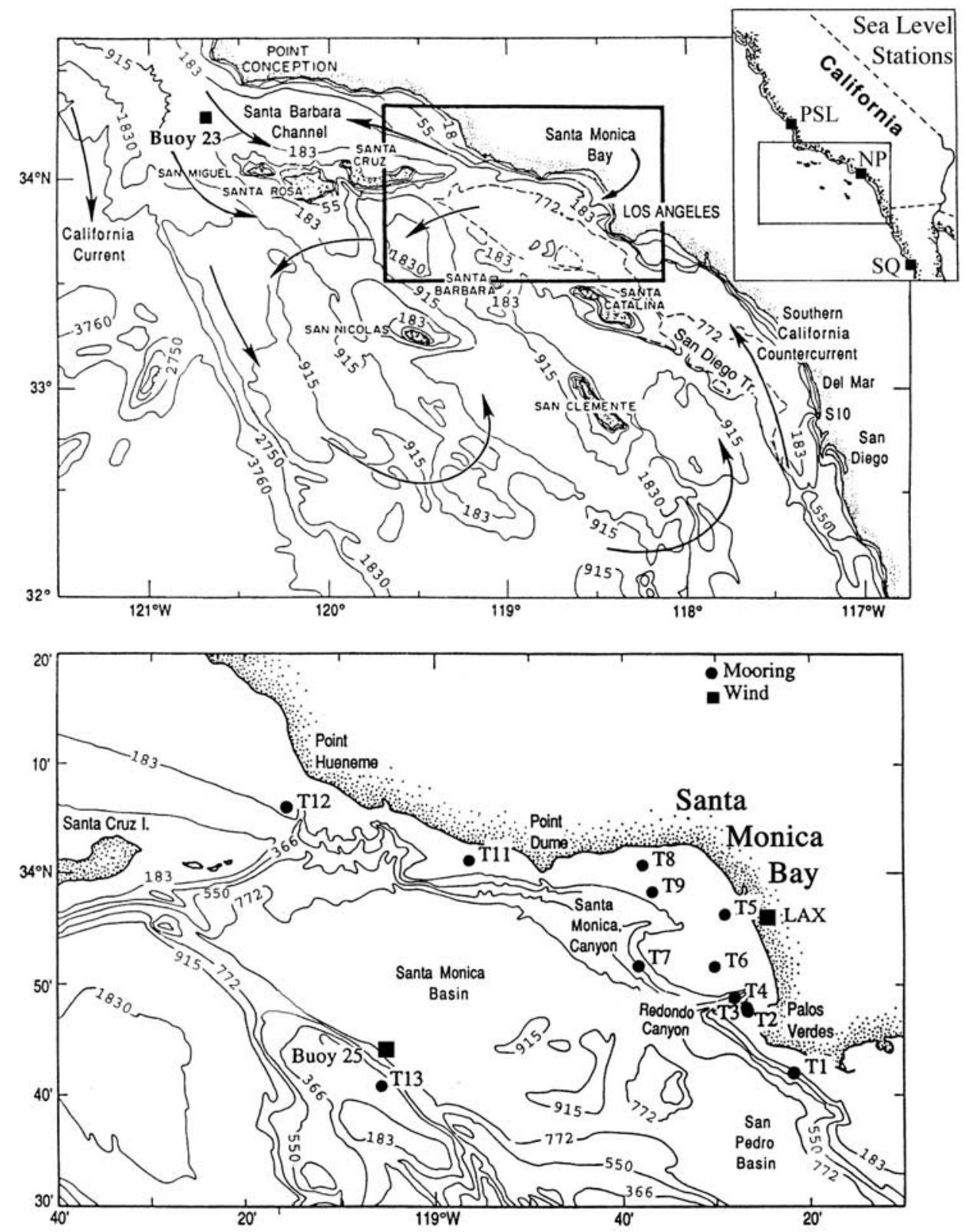

Figure 1. (top) Map of the SC Bight showing bottom topography and schematic mean circulation pattern. Depth contours are given in meters. Sea level stations are shown on the large-scale inset map. The location of the buoy 23 wind station is shown with a solid square. (bottom) Enlarged view of the central SC Bight showing details of local topography such as submarine canyons and headlands as well as locations of moorings and buoy 25 and LAX wind stations.

Conception, turning westward into the bight both north and south of the Channel Islands and warmer water is advected northward along the coast from the south through the bight [Tibby, 1941; Hickey, 1979, 1992, 1993; Bray et al., 1997].

[3] The existing literature describing circulation patterns over the basins within the SC Bight consistently has documented three important characteristics of the eventscale flow field: 1) wind-current correlations are much weaker than in coastal regions outside the bight; 2) timescales of dominant fluctuations are longer than in regions north of the bight (several weeks versus several days); and 3 ) an alongshore pressure gradient (henceforth "APG") is required to explain much of the velocity variability. Meas- urements consistent with these conclusions have been made in the Santa Barbara Channel (henceforth "SB Channel") [Brink and Meunch, 1986; Harms and Winant, 1998], both the Santa Monica and San Pedro Basins (henceforth "SM Basin" or "SM Channel"; "SP Basin" or "SP Channel") [Hickey, 1992], as well as on the coastal shelf/slope of the San Diego Trough [Winant and Bratkovitch, 1981; Winant, 1983; Hickey, 1992].

[4] In the present paper, the source of longer-period (1025 days) variability and its seasonal pattern are explored with a new data set, one that, for the first time, includes data in both the SB Channel (the northern bight) and the SM-SP Channel (the central bight) as well as on the wide semi- 
enclosed shelf adjacent to the channels, Santa Monica Bay (henceforth "SM Bay"). The large-scale nature of the fluctuations is shown for temperature as well as velocity, and much of the temperature variability in the upper $30 \mathrm{~m}$ is shown to result from lateral advection. The most important result from our analyses is a definitive demonstration that the long-period fluctuations responsible for a majority of the velocity variance over the nearshore channels and basins of the central bight as well as on the adjacent shelves can only be accounted for by including an element of forcing outside and south of the bight; i.e., a significant fraction of the variance in the bight is caused by disturbances originating well outside the bight. For the regionally important and heavily polluted SM Bay, we show that the majority of the variance is driven by the large-scale forcing generated outside the bight rather than by local wind stress over the bay. Results for the central bight are combined with previously published results from the northern bight in a schematic model for long-period fluctuations in the entire coastal strip of the SC Bight.

[5] The moored array and ancillary data as well as data analysis techniques are presented in the next section. A qualitative description of the velocity and temperature data and a statistical analysis are given in section 3. Forcing mechanisms for velocity fluctuations are determined in section 4 and the origins of velocity and temperature fluctuations are described in section 5. The paper concludes with a summary and discussion.

\section{Data and Data Analysis Techniques}

[6] The TRANS study included a moored array of fourteen current meter moorings maintained at several sites along the shelf edge and upper continental slope of the central bight and within SM Bay during February-October 1988 (Figure 1). A site on the seaward side of the basin (T13) was occupied for a 6 week period in early spring. A cluster of moorings was also placed around Redondo Canyon to define its role in the circulation. TRANS was one component of the interdisciplinary California Basin Study (CaBS) that took place from 1985 to 1990. Further information as well as physical oceanographic data from TRANS and other studies in the SM-SP region are available at http:/coast.ocean.washington.edu.

[7] Moorings included both surface toroid and subsurface taut wire designs. Vector measuring (VMCMs) or vector averaging (S4s) current meters were used on surface moorings; Aanderaas, VMCMs or RDI Acoustic Doppler Current Profilers (ADCPs) were used on the subsurface moorings. The complete array consisted of twenty nine current meters, including three upward looking ADCPs (Table 1).

[8] Hourly wind speed and direction data were acquired from the National Data Buoy Center for buoy 46023 ("buoy $23^{\prime \prime} ; 34^{\circ} 18^{\prime} \mathrm{N}, 120^{\circ} 42^{\prime} \mathrm{W}$ ), buoy 46025 ("buoy $25^{\prime \prime}$; $\left.33^{\circ} 44^{\prime} \mathrm{N}, 119^{\circ} 05^{\prime} \mathrm{W}\right)$ as well as from Los Angeles International Airport ("LAX"; $33^{\circ} 56^{\prime} \mathrm{N}, 118^{\circ} 24^{\prime} \mathrm{W}$ ) (see locations in Figure 1). Winds at buoy 25 are corrected to a height $10 \mathrm{~m}$ above the sea surface. LAX winds are measured $10 \mathrm{~m}$ above ground; in this study the data were treated as if measured $10 \mathrm{~m}$ above the sea surface. To examine the role of remote wind stress forcing of coastal trapped waves in this region, NCEP/NCAR six hourly winds from the Reanalysis project
Table 1. A Summary of Data Collected During TRANS ${ }^{\mathrm{a}}$

\begin{tabular}{|c|c|c|c|c|}
\hline \multicolumn{5}{|c|}{ MOORING DEPLOYMENTS } \\
\hline $\begin{array}{l}\text { Mooring } \\
\text { ID }\end{array}$ & $\begin{array}{l}\text { Water } \\
\text { Depth } \\
\text { (m) }\end{array}$ & $\begin{array}{l}\text { Data } \\
\text { Depth } \\
\text { (m) }\end{array}$ & $\begin{array}{c}1988 \\
\text { F M A M J A S }\end{array}$ & $\begin{array}{c}\text { Data } \\
\text { Analyzed }\end{array}$ \\
\hline $\mathrm{T} 1$ & 62 & $\begin{array}{l}25 \\
50 \\
55\end{array}$ & - & $\begin{array}{lll}\mathrm{U} & \mathrm{V} & \mathrm{T} \\
\mathrm{U} & \mathrm{V} & \mathrm{T} \\
\mathrm{U} & \mathrm{V} & \mathrm{T}\end{array}$ \\
\hline T2 & 61 & 25 & & $\mathrm{U} \quad \mathrm{V}$ \\
\hline $\mathrm{T} 3$ & 162 & $\begin{array}{c}25 \\
100 \\
130\end{array}$ & --- & $\begin{array}{lll}\mathrm{U} & \mathrm{V} & \mathrm{T} \\
\mathrm{U} & \mathrm{V} & \mathrm{T} \\
\mathrm{U} & \mathrm{V} & \mathrm{T}\end{array}$ \\
\hline $\mathrm{T} 4$ & 182 & $\begin{array}{c}30 \\
50 \\
100 \\
150\end{array}$ & --- & $\begin{array}{ccc}U & V & T \\
U & V & T \\
& |V| & T \\
U & V & T\end{array}$ \\
\hline T5 & 32 & $\begin{array}{c}6-17 \\
28\end{array}$ & $\overline{-------}$ & $\begin{array}{c}\mathrm{U}, \mathrm{V} \text { profiles } \\
\mathrm{T}\end{array}$ \\
\hline T6 & 61 & $14-50$ & 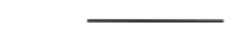 & U,V profiles \\
\hline T7-S & 246 & $\begin{array}{c}5 \\
15\end{array}$ & & $\begin{array}{ccc}U & V & T \\
& |V| & T\end{array}$ \\
\hline $\mathrm{T} 7$ & 244 & $\begin{array}{c}24-140 \\
200\end{array}$ & - & $\begin{array}{l}\mathrm{U}, \mathrm{V} \text { profiles } \\
\mathrm{U} \mathrm{V} \mathrm{T}\end{array}$ \\
\hline T8 & 35 & 5 & & $\begin{array}{lll}\mathrm{U} & \mathrm{V} & \mathrm{T}\end{array}$ \\
\hline T9 & 111 & $\begin{array}{c}25 \\
50 \\
100\end{array}$ & & $\begin{array}{ccc}U & V & T \\
U & V & T \\
U & V & T\end{array}$ \\
\hline T11 & 61 & $\begin{array}{l}30 \\
55\end{array}$ & & $\begin{array}{lll} & |V| & T \\
U & V & T\end{array}$ \\
\hline $\mathrm{T} 12$ & 61 & 50 & & $\begin{array}{lll}\mathrm{U} & \mathrm{V} & \mathrm{T}\end{array}$ \\
\hline T13-S & 256 & 5 & - & $\mathrm{U} \quad \mathrm{V} \quad \mathrm{T}$ \\
\hline $\mathrm{T} 13$ & 249 & $\begin{array}{c}30 \\
100 \\
200\end{array}$ & $\bar{Z}$ & $\begin{array}{lll}U & V & T \\
U & V & T \\
U & V & T\end{array}$ \\
\hline
\end{tabular}

${ }^{a}$ Water depth and data depth are given in meters. Long dashes denote periods for which only temperature data are available. Data include eastwest velocity $(\mathrm{U})$, north-south velocity $(\mathrm{V})$, speed without direction $(|\mathrm{V}|)$, temperature $(\mathrm{T})$, and profiles of $\mathrm{U}, \mathrm{V}$ velocity over the depth range indicated as recorded by an ADCP. Sampling interval for the ADCPs is $1 \mathrm{~m}$ (T5) and $4 \mathrm{~m}$ (T6 and T7). Mooring locations are shown in Figure 1.

[Kalnay et al., 1996] were obtained at $2.5^{\circ}$ intervals between $35^{\circ} \mathrm{N}$ and $22.5^{\circ} \mathrm{N}$ for the grid point closest to the coast. These data are provided by the NOAA-CIRES Climate Diagnostics Center, Boulder, Colorado at http://www. cdc.noaa.gov/. These winds are generated from an atmospheric model that is primarily driven by atmospheric pressure but also includes data assimilated from both coastal buoys and land stations. For the present period, correlation between the NCEP $35^{\circ} \mathrm{N}$ wind stress and buoy 23 stress was high $(\sim 0.85)$ and time series were exactly in phase, suggesting a reasonable relationship to the coastal wind field at least at that one site. Wind stress was computed from hourly data (or six hourly NCEP winds) using a quadratic stress formula and the drag coefficients of Large and Pond [1981]. The appropriate choice of winds for a particular application will be discussed in section 4.2.

[9] Hourly coastal sea level data were obtained just north of the bight (Port San Luis, denoted "PSL", $35^{\circ} 10.6^{\prime} \mathrm{N}$, $120^{\circ} 45.6^{\prime} \mathrm{W}$ ); just south of SM Bay (Newport Beach, denoted "NP", $\left.33^{\circ} 36.2^{\prime} \mathrm{N}, 117^{\circ} 53.0^{\prime} \mathrm{W}\right)$; and south of the bight (San Quintin, denoted “SQ", 30 $29^{\prime} \mathrm{N}, 115^{\circ} 59^{\prime} \mathrm{W}$ ) (see locations on inset map in Figure 1). "Adjusted sea level" was obtained by adding atmospheric pressure (con- 
Table 2. Seasonal Statistics Computed for Selected Subtidal Velocity Data During Spring (February 9 to May 31, 1988) and Summer (June 1 to September 4, 1988) ${ }^{\text {a }}$

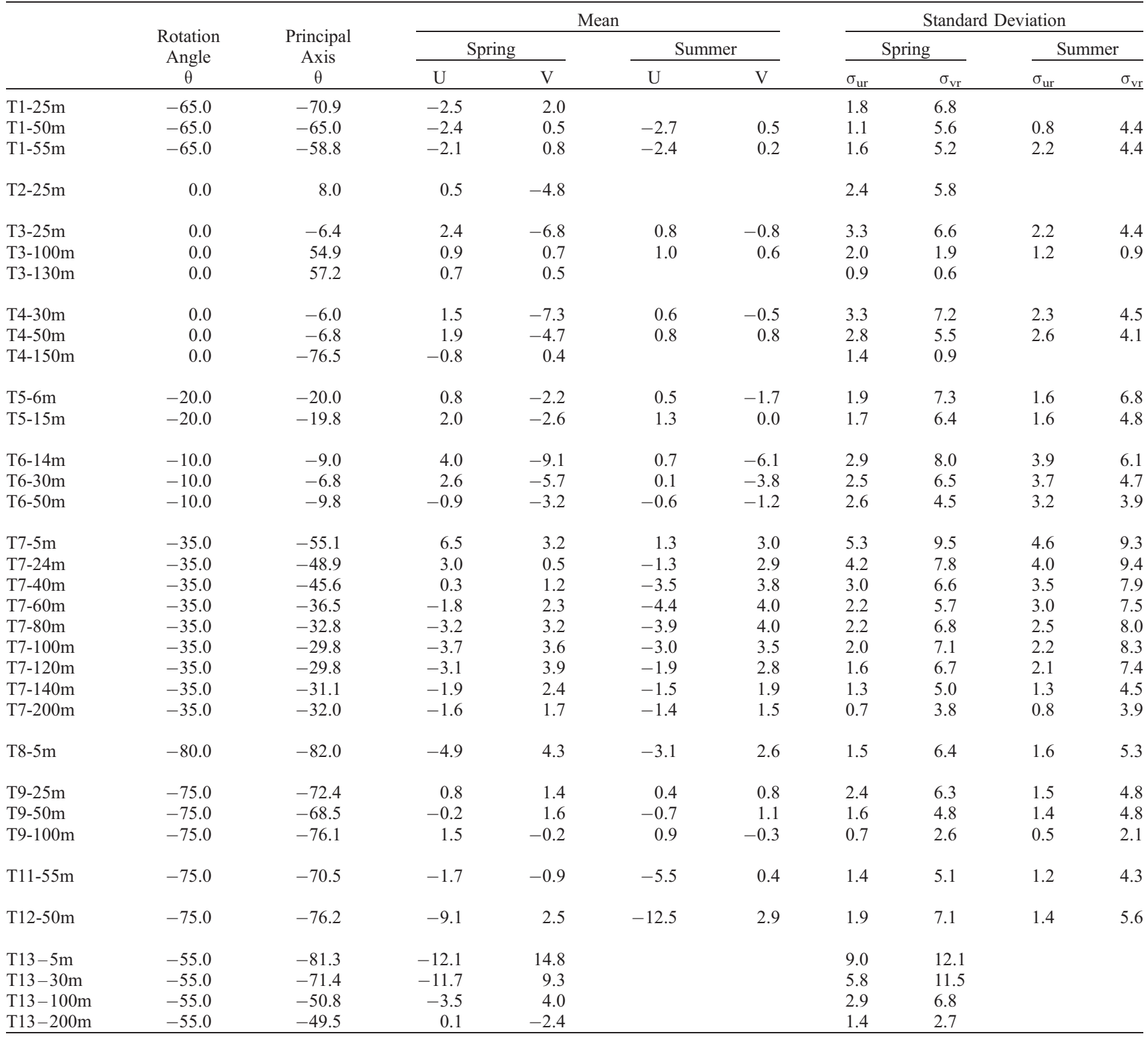

${ }^{\text {a }}$ Velocity units are $\mathrm{cm} \mathrm{s}^{-1}$. Mean east-west $(\mathrm{U})$ and north-south velocity $(\mathrm{V})$ are given in a north-south reference frame (positive eastward and northward, respectively). Standard deviation $\left(\sigma_{\mathrm{ur}}, \sigma_{\mathrm{vr}}\right)$ is given with respect to a local isobath frame of reference. The angle of rotation into a local reference frame as well as the direction of the dominant axis of fluctuations, both calculated over the entire period, are also given.

verted from $\mathrm{mb}$ of pressure to $\mathrm{cm}$ of water) to tide gauge height. Atmospheric pressure data from Port Arguello $\left(34^{\circ} 42.6^{\prime} \mathrm{N}, 120^{\circ} 58.2^{\prime} \mathrm{W}\right)$ were used with Port San Luis sea level data, and data from LAX and San Diego Airports were interpolated to Newport Beach. Spatially interpolated atmospheric pressure data from the NCAR/NCEP reanalysis were used at San Quintin. The record mean (January 1 to October 31, 1988) was removed from each resulting time series.

[10] All time series data were manually edited, filtered to hourly intervals and low-passed with a 40 hour CosineLanczos filter to remove inertial and high-frequency tidal energy. Data were then decimated to six hour values to form the "subtidal" data set. To improve visual representation some time series were further smoothed to remove energy with periods less than 10 days ("long-period" data). For statistical analyses, data were divided into spring (February 9 to May 31) and summer (June 1 to September 4) periods. This seasonal division was chosen because local winds over the central SC Bight decrease significantly after May and also because previous work suggests that the variance due to longperiod remotely forced propagating waves increases after May [Hickey, 1992]. Significance levels were obtained using the number of degrees of freedom estimated from the record length divided by the autocorrelation timescale [Davis, 1976], with significance levels taken from Koopmans [1974].

[11] For some analyses, current vectors were rotated into a local isobath frame of reference. For each mooring, a rotation angle was chosen based on the orientation of the local coastline or shelf break (Table 2). Winds were rotated 


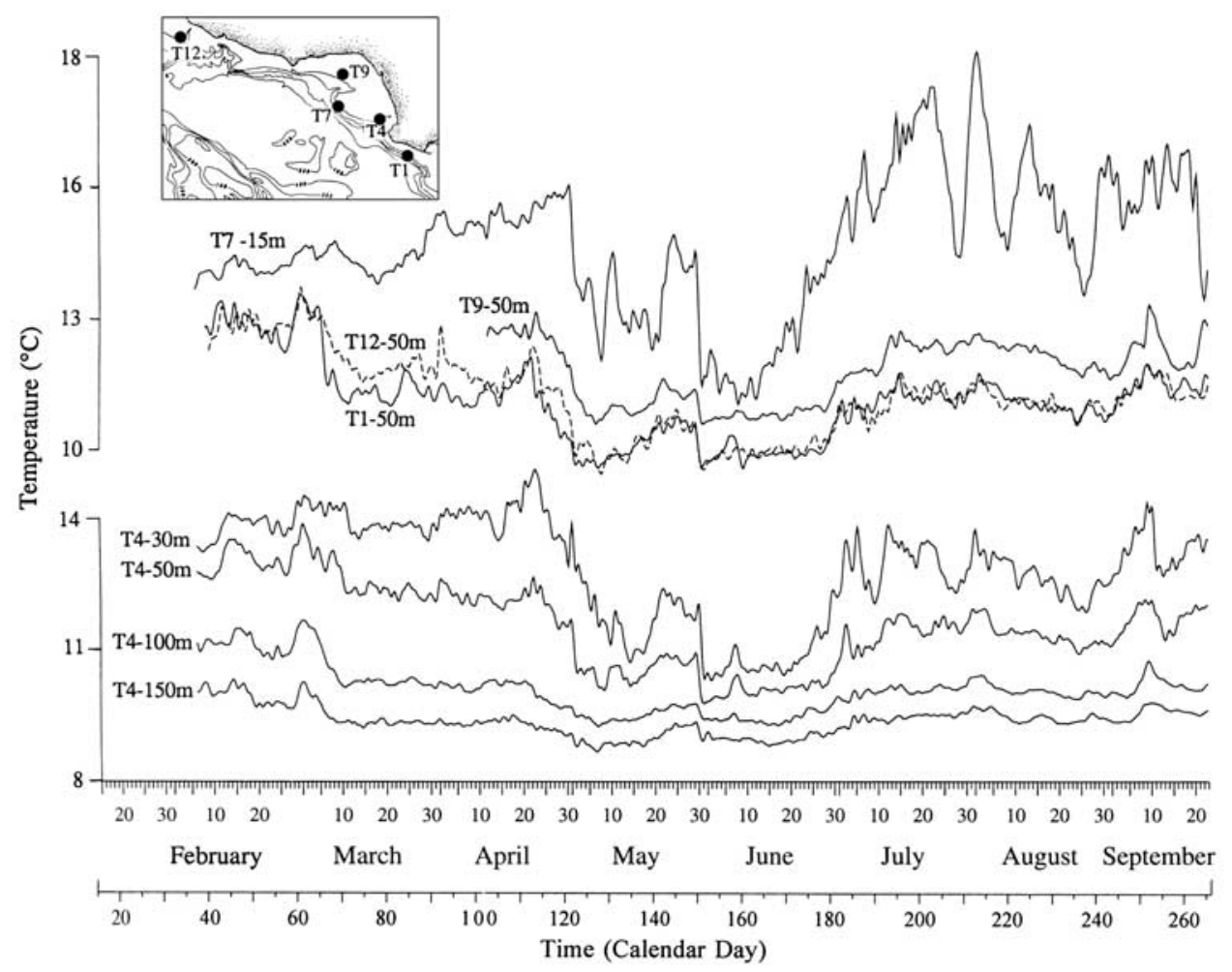

Figure 2. Time series of temperature measured at selected locations and depths throughout the study area. Mooring locations are shown on the inset map. Data at T9, $50 \mathrm{~m}$ are offset by $1.0^{\circ} \mathrm{C}$ from other $50 \mathrm{~m}$ data to better delineate any spatial differences.

by $-30^{\circ}$, the orientation of the coastline, at LAX and by $-55^{\circ}$, the orientation of the axis of SM Basin, at buoy 25 . Rotated velocity components are denoted alongshore $\left(\mathrm{v}_{\mathrm{r}}\right.$, positive poleward) and cross shore ( $\mathrm{u}_{\mathrm{r}}$, positive onshore).

[12] To obtain estimates of the spatial and temporal scales of dominant processes, Empirical Orthogonal Functions (EOFs) were computed in the time domain [Kundu and Allen, 1976]. Velocity EOF modes were computed using a data matrix consisting of north-south and east-west currents for each location and resulting eigenfunctions were plotted as vectors.

[13] Water property surveys of the central bight were performed in February, April and October 1988. A Neil Brown Mark III CTD with sensor accuracies of \pm 0.003 psu and $\pm 0.0011^{\circ} \mathrm{C}$ was used to obtain CTD profiles.

\section{Temperature and Currents in the Central Bight}

\subsection{Temperature}

[14] Temperature records demonstrate that dominant temperature fluctuations are spatially coherent over the $\sim 100$ $\mathrm{km}$ extent of the study region (Figure 2). A strong seasonal variation is observed at all locations and depths: water is coldest in May and June, when several of the largest equatorward (upwelling favorable) wind-forced current events also occur (see section 4). Temperature is warmest in winter at below-pycnocline depths $(>30 \mathrm{~m})$ but in summer at above-pycnocline depths. The seasonal range of temperature is about $4^{\circ} \mathrm{C}$ at $50 \mathrm{~m}$ but $7^{\circ} \mathrm{C}$ at $15 \mathrm{~m}$ where significant seasonal heating is observed. Fluctuations with amplitudes of several degrees and relatively long periods of tens of days are superimposed on seasonal trends. It is these fluctuations and associated current fluctuations that are the primary focus of this paper.

[15] Vertical profiles of temperature at seasonal intervals show the seasonal progression of mixed layer depth over the shelf and slope, from greater than $50 \mathrm{~m}$ in winter to less than $20 \mathrm{~m}$ in early fall (Figure 3). Vertical gradients are significant in the upper $200 \mathrm{~m}$ in all seasons. Thus, a temperature decrease of $3^{\circ} \mathrm{C}$ in spring at $30 \mathrm{~m}$ could represent a vertical excursion of about $40 \mathrm{~m}$; a warming of $2^{\circ} \mathrm{C}$ at $30 \mathrm{~m}$ in summer could represent an excursion of as little as $10 \mathrm{~m}$. Although such excursions may be possible because of isopycnal tilting with geostrophic adjustment, our analysis of these fluctuations will demonstrate that the majority of the temperature changes in Figure 2 are more likely due to lateral, rather than vertical advection.

[16] Variance preserving spectra calculated for the entire 9 month record at locations on the shelf and at the entrance to the SB Channel confirm that the majority of the variance in the temperature records occurs at periods greater than 10 days (Figure 4). The largest variance occurs at a period of $51 \mathrm{~d}$. The longest periods represent primarily the dramatic seasonal decrease in temperature in May and June. The amplitude of the variance decreases by about half between the 50 and $25 \mathrm{~m}$ depths shown.

[17] EOF analysis confirms the high degree of spatial correlation between temperature records (Figure 5). The first EOF in spring accounts for $75 \%$ of the total variance, and the first two EOFs together account for $92 \%$ of the variance. In summer, the percent variance accounted for by 


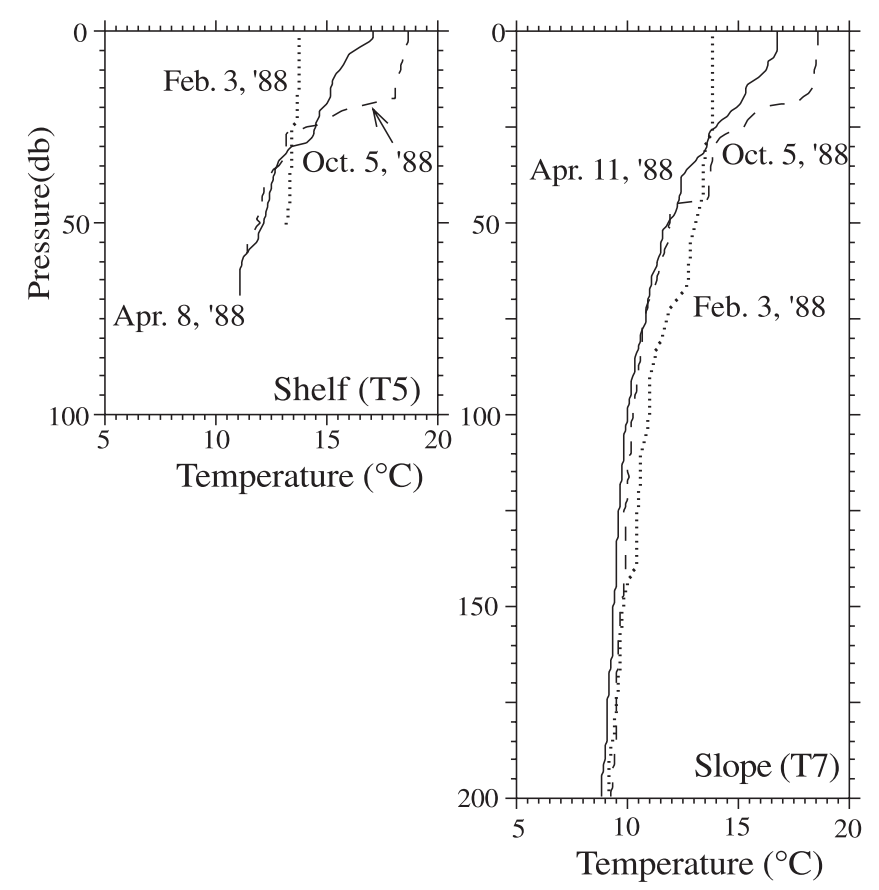

Figure 3. Typical temperature profiles in three seasons on the shelf (near T5) and slope (near T7) of the central bight.

the first mode is $91 \%$, even higher than in spring. Modal structure is layered strongly by depth in both seasons. However, in spring, amplitudes have a subsurface maximum at 30 to $50 \mathrm{~m}$; in summer, amplitudes decay away from the sea surface. The vertical amplitude gradient over $200 \mathrm{~m}$ is approximately sixfold in spring but approximately tenfold in summer.

\subsection{Currents}

\subsubsection{Mean Current Patterns}

[18] The central SC Bight is topographically complex and circulation patterns are largely steered by the local topography (Figure 1). The deep ( $\sim 900 \mathrm{~m})$ SM-SP Basin seaward of SM Bay connects via a shallow ( $200 \mathrm{~m})$ sill to the shallower $(\sim 600 \mathrm{~m}) \mathrm{SB}$ Channel to the northwest and to the deeper $(\sim 1000 \mathrm{~m})$ San Diego Trough to the southeast. The shelf on the shoreward side of the basin is a broad, shallow, and topographically complex region known as Santa Monica Bay. This bay, which is just offshore of Los Angeles, has been heavily polluted by industrial and agricultural activity over the past 100 years. The present data set is the first comprehensive data set describing circulation in this locally important region. The bay's length, curving from Point Dume in the northwest to the Palos Verdes peninsula in the southeast, is about $45 \mathrm{~km}$. North and south of the bay the shelf is relatively narrow $(\sim 7 \mathrm{~km})$, whereas inside the bay the shelf is wider $(\sim 20 \mathrm{~km})$ and is incised by two submarine canyons. Santa Monica Canyon $(\sim 5 \mathrm{~km}$ width) bisects the bay and Redondo Canyon ( $\sim 2 \mathrm{~km}$ width) incises more than halfway across the shelf in the southern part of the bay. Average bottom depth in the bay is about $55 \mathrm{~m}$.

[19] Seasonal mean velocities and standard deviations are summarized in Table 2. Mean circulation patterns for SM Bay in both spring and summer show a double gyre, with equatorward flow in the southeastern half of the bay and poleward flow in the northwestern half (Figure 6). In the surrounding area, flow is poleward along the continental slope and the shelves to the north and to the south of the bay as well as on the ridge on the seaward side of SM Basin roughly $40 \mathrm{~km}$ from the coast, consistent with seasonal flow patterns expected for the California Current system in this region (see schematic in Figure 1). In spring, mean flow is directed into the bay near the surface over the slope.

[20] Although the spatial structure of the currents is similar in the two seasons, the amplitude of currents at individual sites has significant seasonal variation. For example, equatorward currents in the southern part of the bay are stronger in spring, whereas poleward flow along the slopes and channels is stronger in summer. On the other hand, mean inflow from the slope to the shelf is weaker in summer than in spring. The seasonal increase in poleward flow along the slope and channels is the signature of the seasonal variation of the large-scale Southern California Countercurrent [Hickey, 1992].
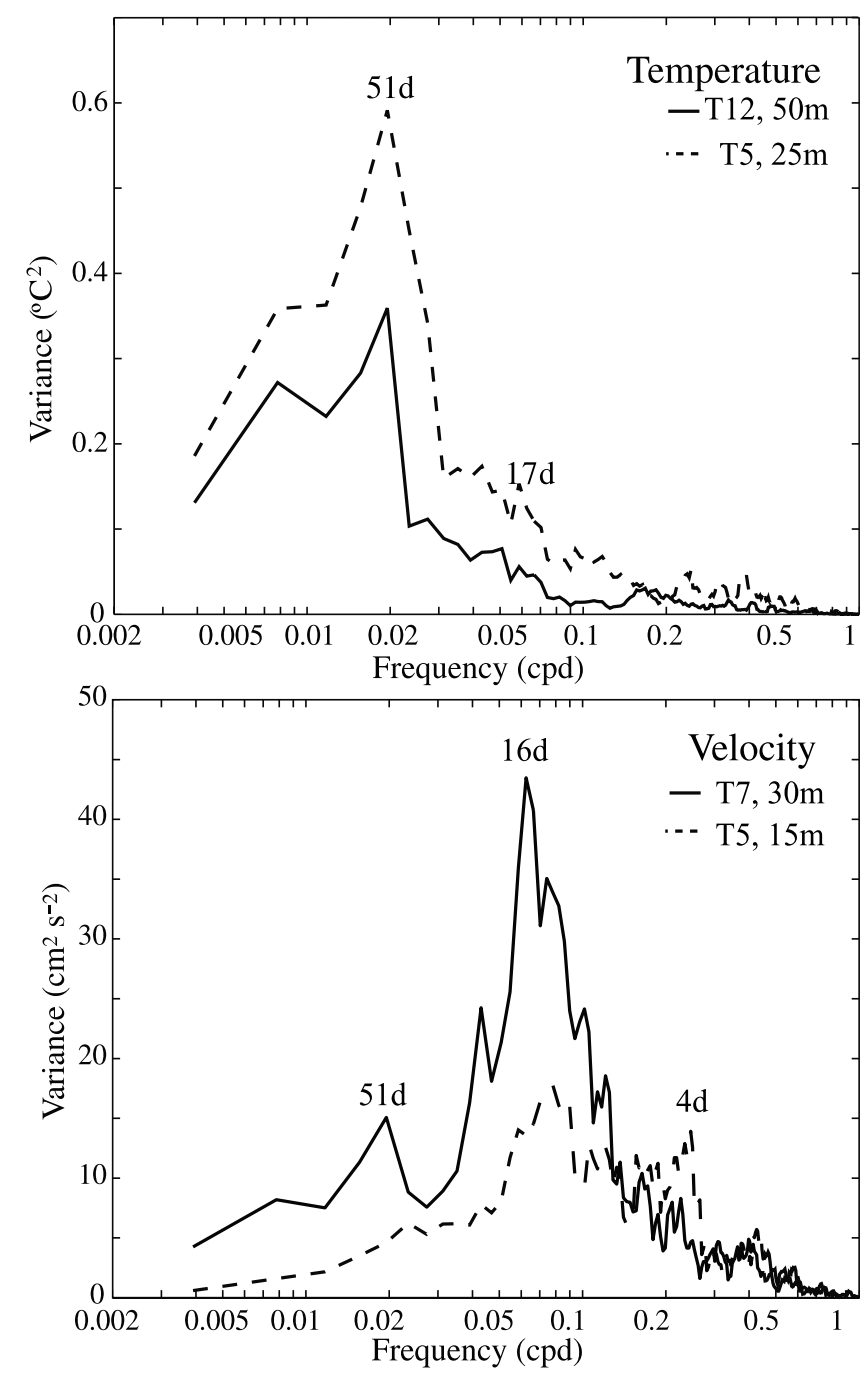

Figure 4. Variance preserving spectra calculated using 9 month records at selected (top) temperature and (bottom) velocity sites over the shelf (T5 and T12) and slope (T7). 
[21] Redondo Canyon has little influence on the direction of upper water column mean currents in the spring: currents measured at 30 and $46 \mathrm{~m}$ over the canyon follow the coastline and not the canyon walls (Figure 6). However, below the lip of the canyon in spring, weak mean currents follow the walls cyclonically around the canyon as observed in other coastal canyons [Hickey, 1997]; see flow at 100 and $150 \mathrm{~m}$ in Figure 9 of S. E. Allen and B. M. Hickey (Dynamics of advection-driven upwelling over a shelf-break submarine canyon, submitted to Journal of Physical Oceanography, 2002).

\subsubsection{Fluctuating Currents}

[22] Large-amplitude velocity fluctuations occur at all locations in the central bight and the fluctuations have relatively long periods (Figure 7). Variance preserving spectra for 9 month records on both the shelf and slope confirm that the majority of the variance occurs at periods greater than 10 days (Figure 4). Maximum energy is observed at a period of about 16 days at $30 \mathrm{~m}$ (Figure 4). The period of dominant variance is similar to that reported in other years and at other sites in the SC Bight ( 20-25 days [Hickey, 1992] and $\sim 14$ days [Auad and Hendershott, 1997]). Fluctuations in the range 10-25 days will be denoted "long period". At the shelf location, more of the variance occurs at periods less than 10 days, although longer periods are still dominant.

[23] The records displayed in Figure 7 illustrate that correlations between sites are much weaker than typically observed in shelf areas north of Point Conception [Winant et al., 1987]. Indeed, site-to-site spatial correlation scales are

\section{TEMPERATURE EIGENFUNCTIONS}

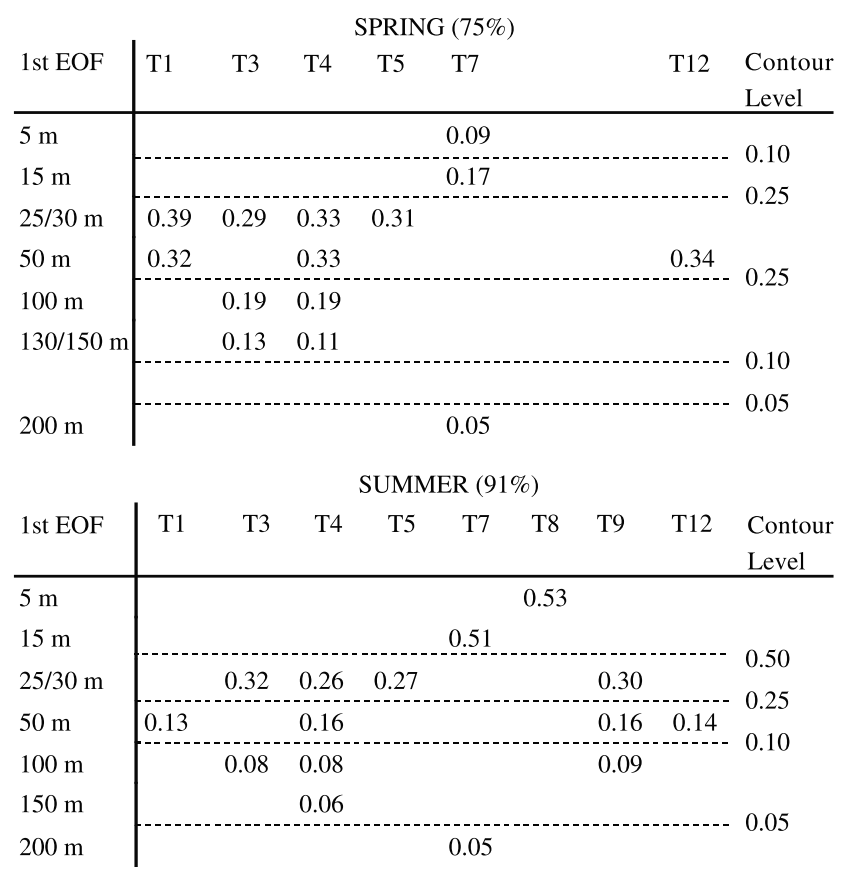

Figure 5. Spatial structure of the first temperature eigenfunctions for spring (February 9 to May 31, 1988) and summer (June 1 to September 4, 1988). Values are arranged from left to right according to mooring ID (generally from south to north) and measurement depth. Approximate contour levels are shown with dotted lines.
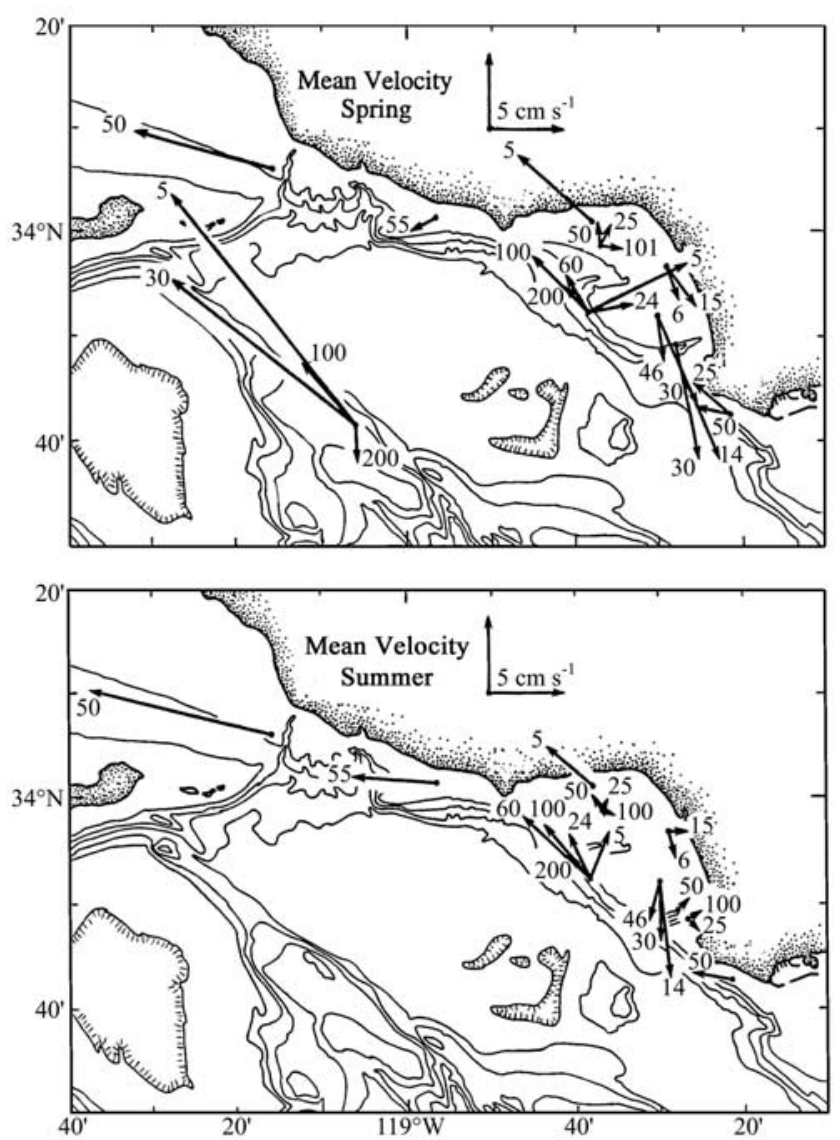

Figure 6. Selected mean currents for spring and summer. Measurement depth in meters is given near the tip of each arrow. Bathymetric contours are the same as in Figure 1 (bottom).

relatively short $(10-15 \mathrm{~km}$ for a $95 \%$ level of significance, not shown). Nevertheless, EOF analysis in the time domain shows that about half the velocity variance resides in scales that exceed the $\sim 80 \mathrm{~km}$ length of the study area (Figure 8 ). EOF-derived spatial patterns are similar in spring and summer: one mode is unidirectional over the shelf and slope with similar amplitudes at most sites; the second has a reversal over the shelf in comparison to the adjacent slope with greatest amplitudes at the deeper site adjacent to SM Bay. The relative importance of the two EOF patterns differs between seasons, with the unidirectional mode accounting for more variance in spring and the countercurrent mode, in summer. Our analysis in section 4.3 will show that the dominance of the unidirectional mode in spring is a result of substantial contributions to the velocity field from direct local wind stress driving, which tend to be in the same direction over both shelf and slope. We will show that in summer, local wind stress in this region is too weak to significantly contribute to alongshore velocity variance on the shelf.

[24] The first mode accounts for less than $40 \%$ of the total variance in both seasons. However, the sum of the first two modes accounts for $57 \%$ of the total variance in spring and $52 \%$ of the total variance in summer. At individual measurement sites on the slope as much as $79 \%$ and $88 \%$ of the variance is accounted for in spring and summer, respec- 


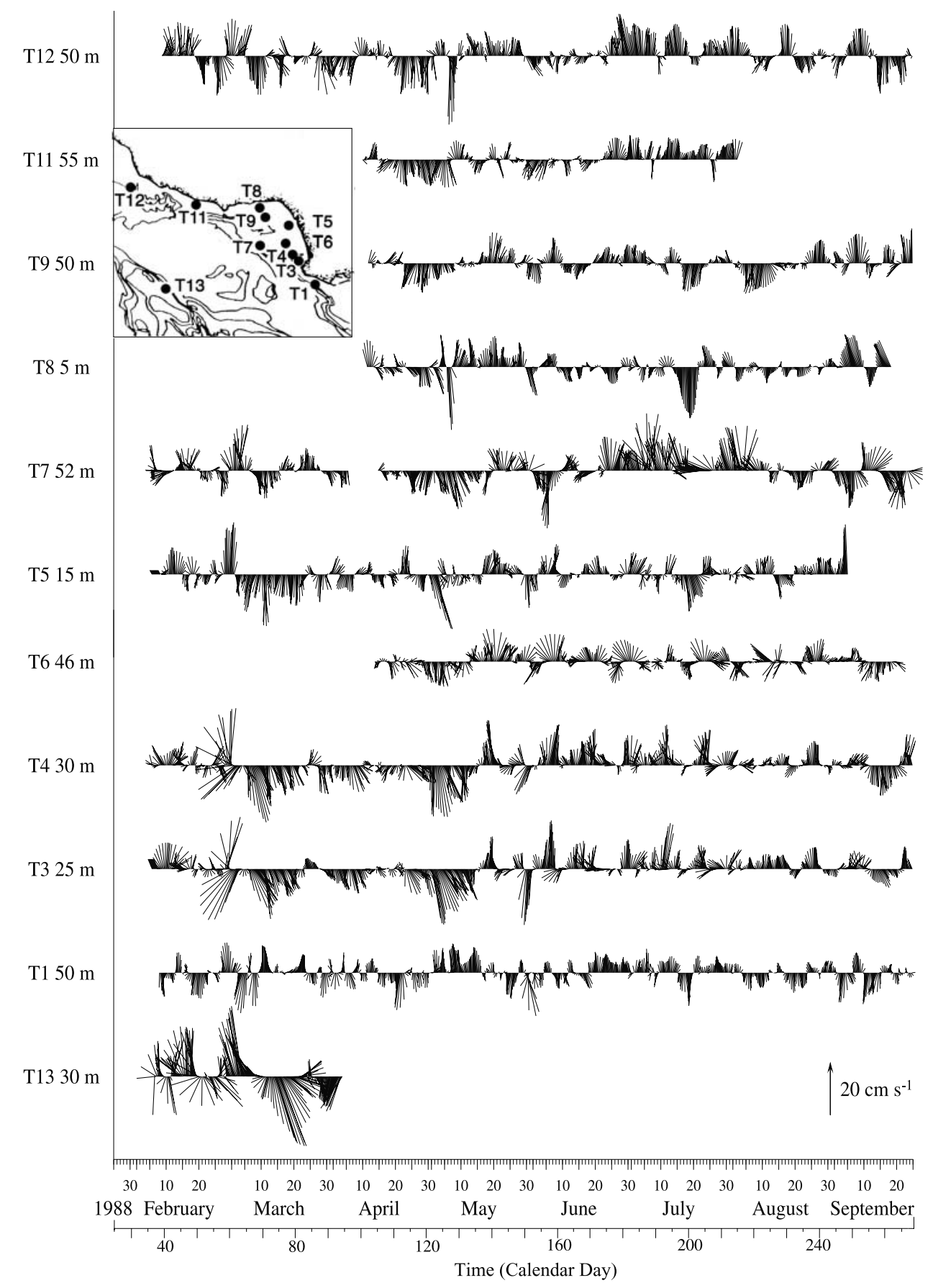

Figure 7. Vector time series of de-meaned subtidal currents at selected depths and locations in a local isobath frame of reference (positive poleward and onshore). Means and rotation angles are given in Table 2. Time series are plotted with the most northern mooring at the top of the page, proceeding southward along the shelf and channel. Data from the mooring on the west of SM Basin are shown at the bottom.

tively; on the SM shelf, $89 \%$ and $65 \%$, in spring and summer, respectively. Time series of the first two EOF modes are significantly coherent at low frequencies in both seasons, with the unidirectional mode leading the countercurrent mode by about 2-4 days in both seasons (not shown). This suggests that the two modes may be dynamically related. A possible mechanism linking slope flow with shelf counterflow is presented in a numerical model study in section 4.4 .
[25] To delineate velocity vertical structure more clearly, EOF analysis was also performed at individual sites over the slope and shelf (Figure 9). The first velocity EOF at the slope site accounts for $64 \%$ of the total variance in spring and $68 \%$ in summer and represents much of the same large-scale variance as the first EOF calculated over the entire region (amplitude time series not shown). The dominant fluctuations represented by this EOF mode in both seasons are predominantly alongshore as well as 

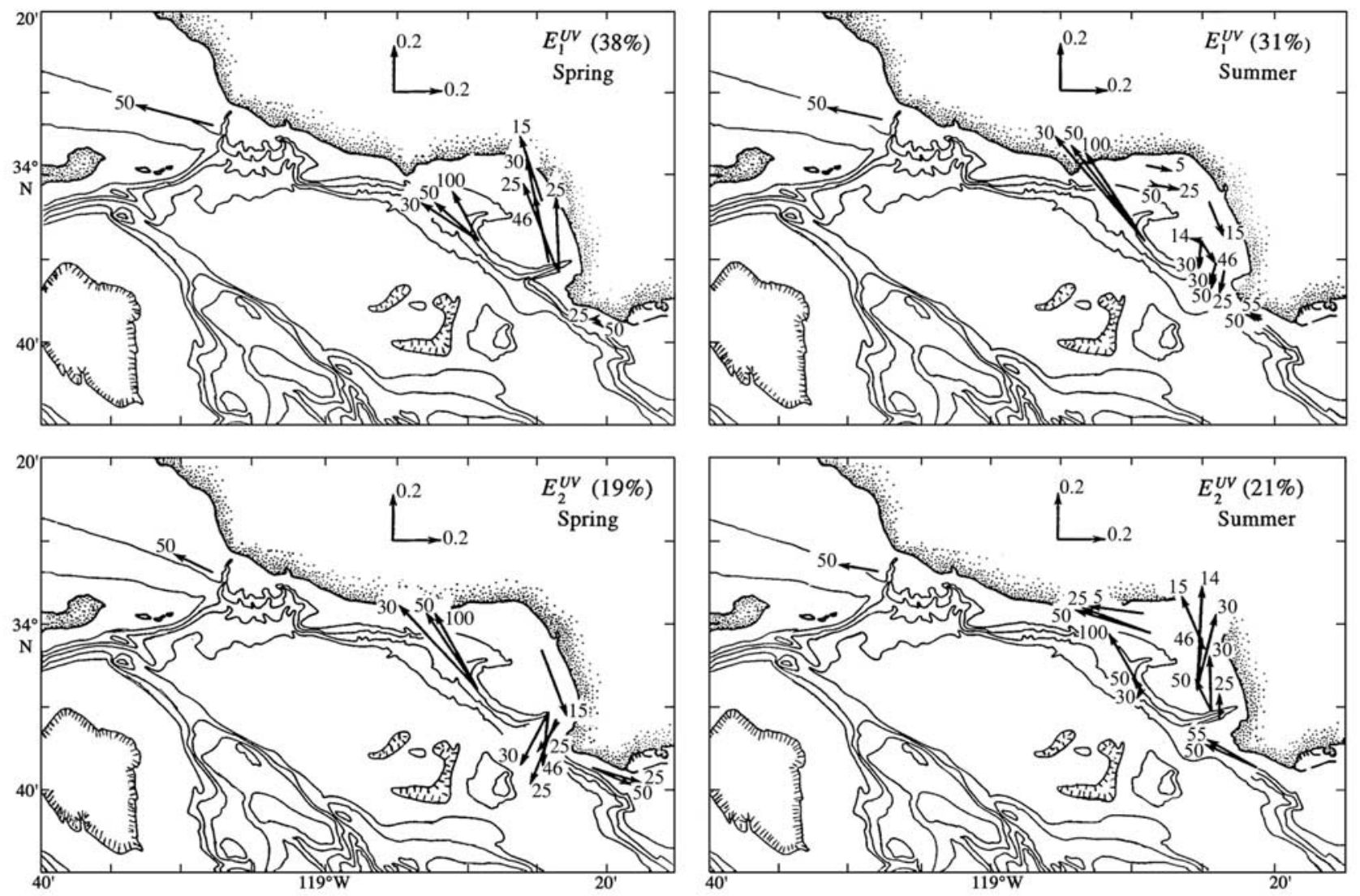

Figure 8. Spatial structure of the first $\left(\mathrm{E}_{1}{ }^{\mathrm{UV}}\right)$ and second $\left(\mathrm{E}_{2}{ }^{\mathrm{UV}}\right)$ velocity eigenfunctions for (left) spring and (right) summer. Stations with ADCP profilers were subsampled with depth to avoid overweighting a single location. Measurement depth in meters is given near the tip of each arrow. Bathymetric contours are the same as in Figure 1 (bottom).

quasi-barotropic; i.e., no direction reversals occur over the upper $200 \mathrm{~m}$ of the water column. A subsurface maximum occurs at $80-100 \mathrm{~m}$ in both seasons as observed in the previous year at the same site [Hickey, 1992]. Although the first mode is barotropic, vertical shear over the $200 \mathrm{~m}$ included in the EOF is substantial: the amplitude decreases by at least one third between 40 and $140 \mathrm{~m}$. The second mode, like the first, is oriented mainly alongshore, and also has a subsurface maximum near $100 \mathrm{~m}$. The second mode is more highly sheared than the first mode. The subsurface maximum in variance in both EOF modes is roughly coincident with a mean poleward velocity maximum, likely the signature of the California Undercurrent. In this data set the core of the California Undercurrent over the SM Basin shoals from $100 \mathrm{~m}$ to $60 \mathrm{~m}$ between spring and summer.

[26] Although the dominant fluctuations over the basin slope are quasi-barotropic, they are not in phase through the water column at an individual site. For example, at T7 on the SM slope, a $\sim 2$ day lag is observed between 100 and $200 \mathrm{~m}$ (Figure 10a), a phase difference of about $36^{\circ}$ for a 20 day signal (significant at the $90 \%$ level). Fluctuations occur earlier at deeper depths. Similar vertical lags were observed at the site on the opposite side of the basin (T13) in the same bottom depth (not shown). Fluctuations are also lagged between sites with different bottom depths: fluctuations in shallower bottom depths precede those in deeper depths.
For example, at $50 \mathrm{~m}$, a statistically significant lag of 1.5 days $\left(30^{\circ}\right.$ for a 20 day signal) occurs between fluctuations in bottom depths of $61 \mathrm{~m}$ and $245 \mathrm{~m}$ (Figure 10b). Similar cross-shore lags have been demonstrated in this region in two other years [Hickey, 1992].

[27] The first velocity EOF at the shelf site accounts for $90 \%$ of the total variance in spring and $87 \%$ in summer. Dominant velocity fluctuations are quasi-barotropic as on the slope, but have no subsurface maximum. The mean flow, on the other hand, has significant vertical shear, with equatorward flow increasing away from the sea surface in both seasons to $14 \mathrm{~m}$ in summer and to greater than $17 \mathrm{~m}$ (the last measurement depth) in spring. Cross-shore currents on the shelf as well as vertical shear in alongshore currents are primarily represented by the second mode which accounts for $6 \%$ or less of the variance in either season. Like the mean flow, vertical shear is greater in spring than in summer. No clear evidence of an Ekman spiral is observed in either season.

\section{Dynamics of Currents in the Central Bight \\ 4.1. Interrelationships Among Variables}

[28] Representative time series of alongshore winds at a location on the seaward side of the SM Basin (buoy 25), and on the landward side of the SM Basin (LAX), adjusted local sea level, the first temperature EOF and the unidirectional 
SHELF
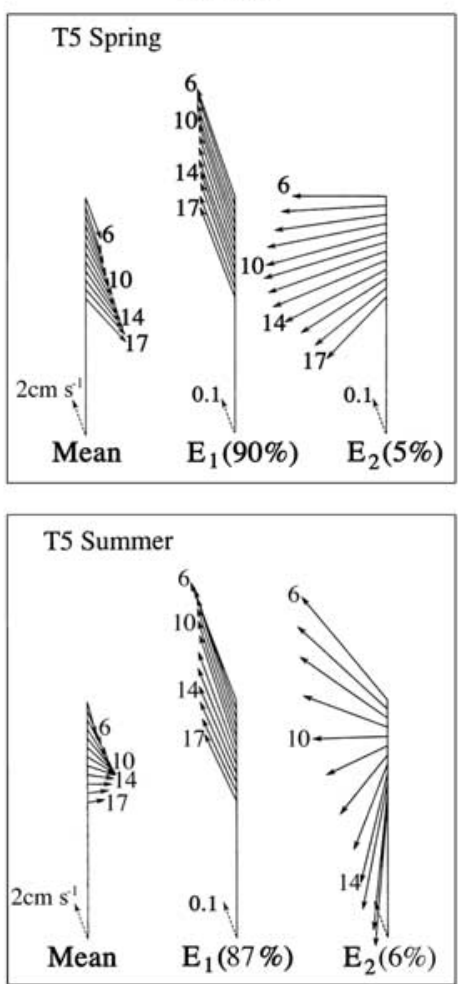

SLOPE
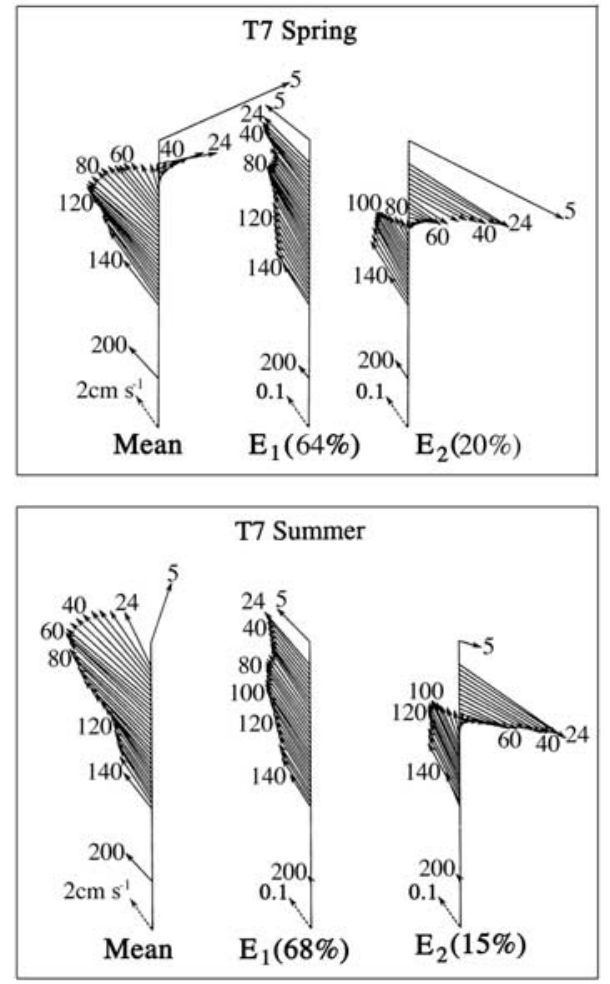

Figure 9. Detailed vertical structure of mean velocities and temporal EOFs for the inner shelf (T5, bottom depth $32 \mathrm{~m}$ ) and slope (T7, bottom depth $245 \mathrm{~m}$ ) of the central bight for spring and summer. Arrows at the base of each column provide the scale and are oriented along local isobaths. Measurement depth in meters is given for selected vectors.

and countercurrent current EOF modes are shown in Figure 11. The seasonal structure of the first temperature mode and adjusted local sea level are similar. Alongshore velocity is not as strongly seasonal as temperature and adjusted sea level.

[29] Velocity EOF time series show some similarity to the temperature and sea level records on shorter-than-seasonal scales. For example, strong equatorward winds appear to be associated with equatorward flow in the unidirectional mode and with decreases in both temperature and local sea level; and poleward winds are frequently associated with higher temperatures in spring. Some temperature maxima correspond to extrema in both poleward velocity and local sea level. Coherence and phase analyses (not shown) show that coherence between velocity EOF modes, temperature EOF modes, wind and sea level is much higher in spring than in summer, with typical values of $0.6-0.8$ versus $0.3-0.4$. Significant coherence in spring $(>0.55$ for the $90 \%$ level) occurs primarily in two frequency bands, one with periods of 4-6 days; the other with periods of 10-25 days. As discussed previously the long-period band contains the majority of the alongshore velocity variance in the central bight. With the exception of wind, coherence of time series with the first velocity EOF mode is much higher at long periods than at short periods $(\sim 0.8$ versus $\sim 0.6)$. Coherence with wind is barely significant at long periods, but relatively high for short periods $(\sim 0.8)$. At short periods, wind leads currents by less than a day as expected
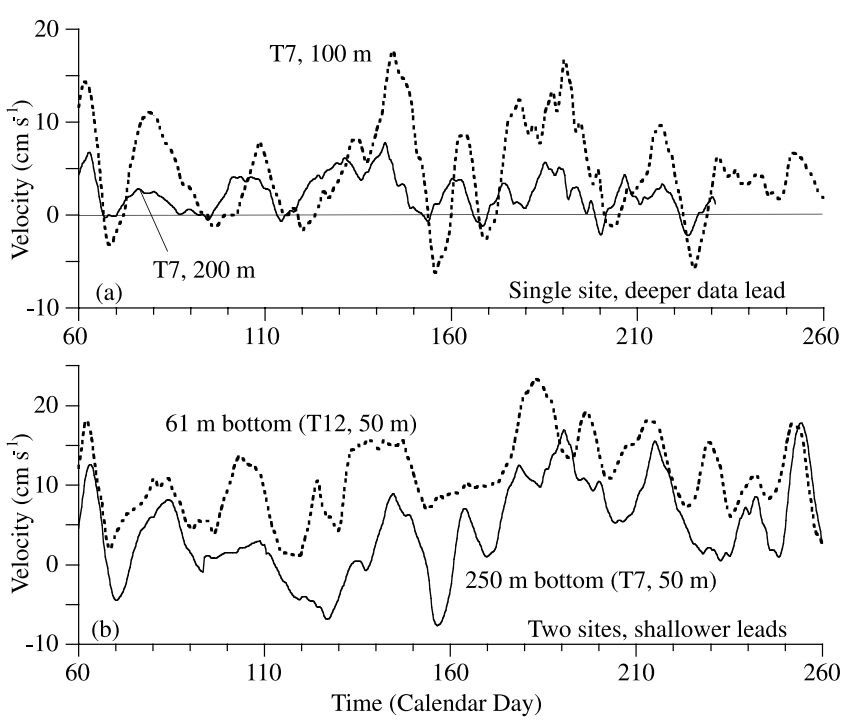

Figure 10. (a) Comparison of long-period observed alongshore flow at $100 \mathrm{~m}$ and $200 \mathrm{~m}$ on the SM slope. Deeper fluctuations occur earlier. (b) Comparison of longperiod observed alongshore flow at $50 \mathrm{~m}$ at two sites in different bottom depths: T12 (61 m bottom depth) and T7 ( $245 \mathrm{~m}$ bottom depth). Fluctuations in the shallower bottom depth occur first. 


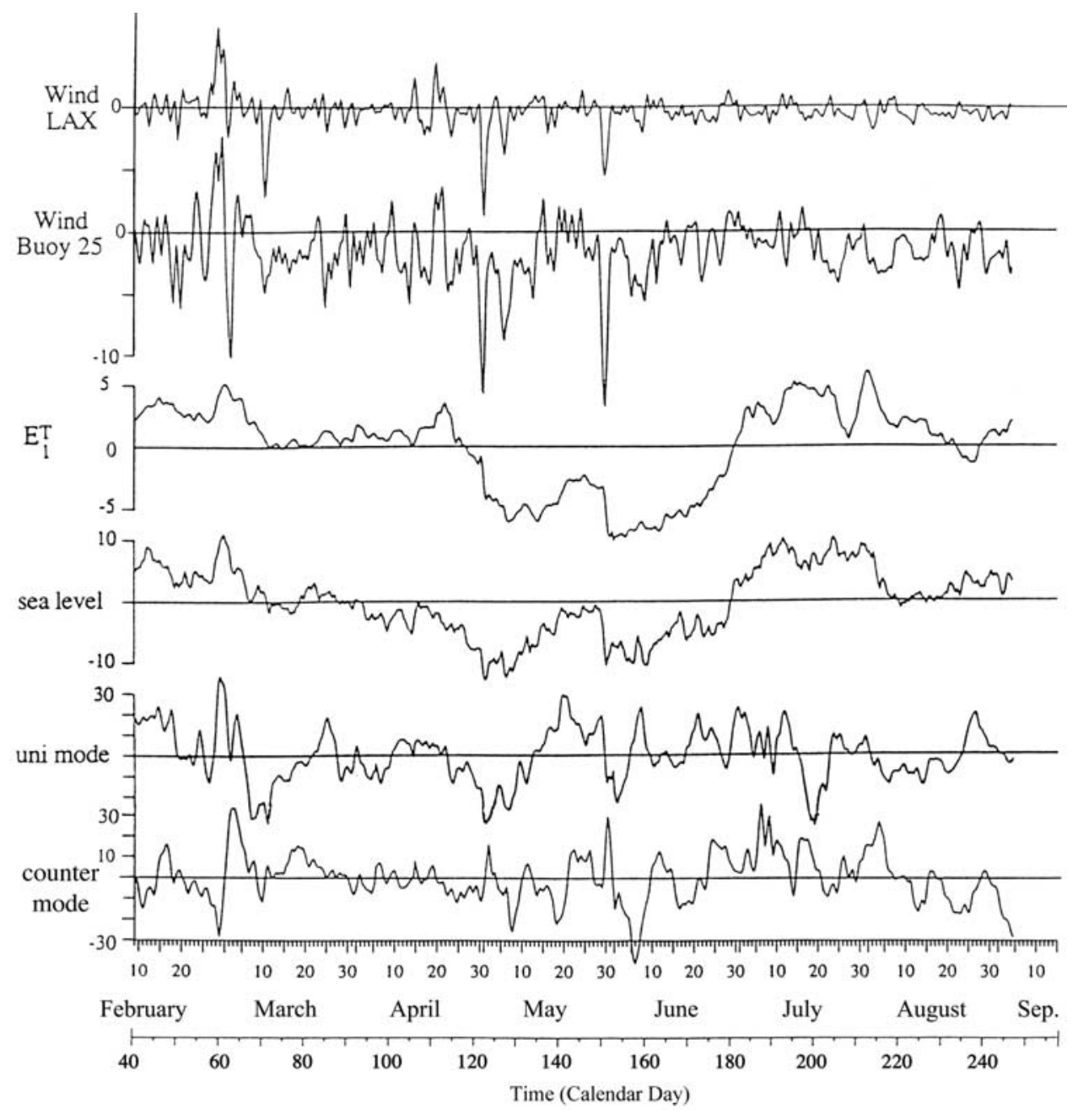

Figure 11. From top to bottom: time series of alongshore wind (top two panels, $\mathrm{m} \mathrm{s}^{-1}$ ), first temperature EOF mode $\left({ }^{\circ} \mathrm{C}\right)$, adjusted sea level at Newport $(\mathrm{cm})$, and the first two velocity EOFs $(\mathrm{cm}$ $\mathrm{s}^{-1}$ ). The unidirectional EOF mode combines the first EOF in spring with the second EOF in summer; the countermode combines the second EOF in spring with the first EOF in summer.

for alongshore wind driving of alongshore flow. In summer, only the first mode velocity and temperature EOFs are significantly coherent at long periods. Sea level, temperature and wind are more strongly correlated at short periods, but the coherence occurs in narrow frequency bands and is barely significant at the $90 \%$ level, suggesting that the relationship is not robust.

[30] Thus, the observations show that a) $50-60 \%$ of the total velocity variance and as much as $90 \%$ at individual sites on both the shelf and slope have an alongshore scale exceeding the length of the SM-SP Basin; b) these fluctuations have the majority of their energy at longer periods (10-25 days); c) local alongshore wind stress likely has a significant role in spring but not in summer; d) both lateral and vertical phase lags are significant; and, e) temperature fluctuations are also predominantly largescale and long-period and are related to the velocity fluctuations. In the following section possible forcing mechanisms for long-period fluctuations in the velocity field are considered in order to estimate the fraction of the velocity variance associated with each process in each season. Mechanisms examined include acceleration by local wind stress and by alongshore pressure gradients as well as local topographic effects. The origins of longperiod water property fluctuations are considered in a subsequent section. Results are combined with previous research in other areas of the bight and presented in section 6 as a conceptual model for long-period circulation in the coastal strip of the SC Bight.

\subsection{Selection of Forcing Mechanisms to Model the} Flow Field

\subsubsection{Alongshore Wind Stress}

[31] Wind at three locations were included in the primary regional analysis: LAX airport, representing nearshore winds in SM Bay; buoy 25, representing winds over the basin side of SM Bay and the channels; and buoy 23, representing winds seaward of the bight yet near Point Conception (see locations in Figure 1). Comparison of vector time series illustrates a shoreward decrease of wind amplitude, consistent with seasonal patterns described by Winant and Dorman [1997] (Figure 12). Winds at buoy 23 are strongly upwelling favorable (equatorward) throughout the year in contrast to stations closer to the coast. Winds at 


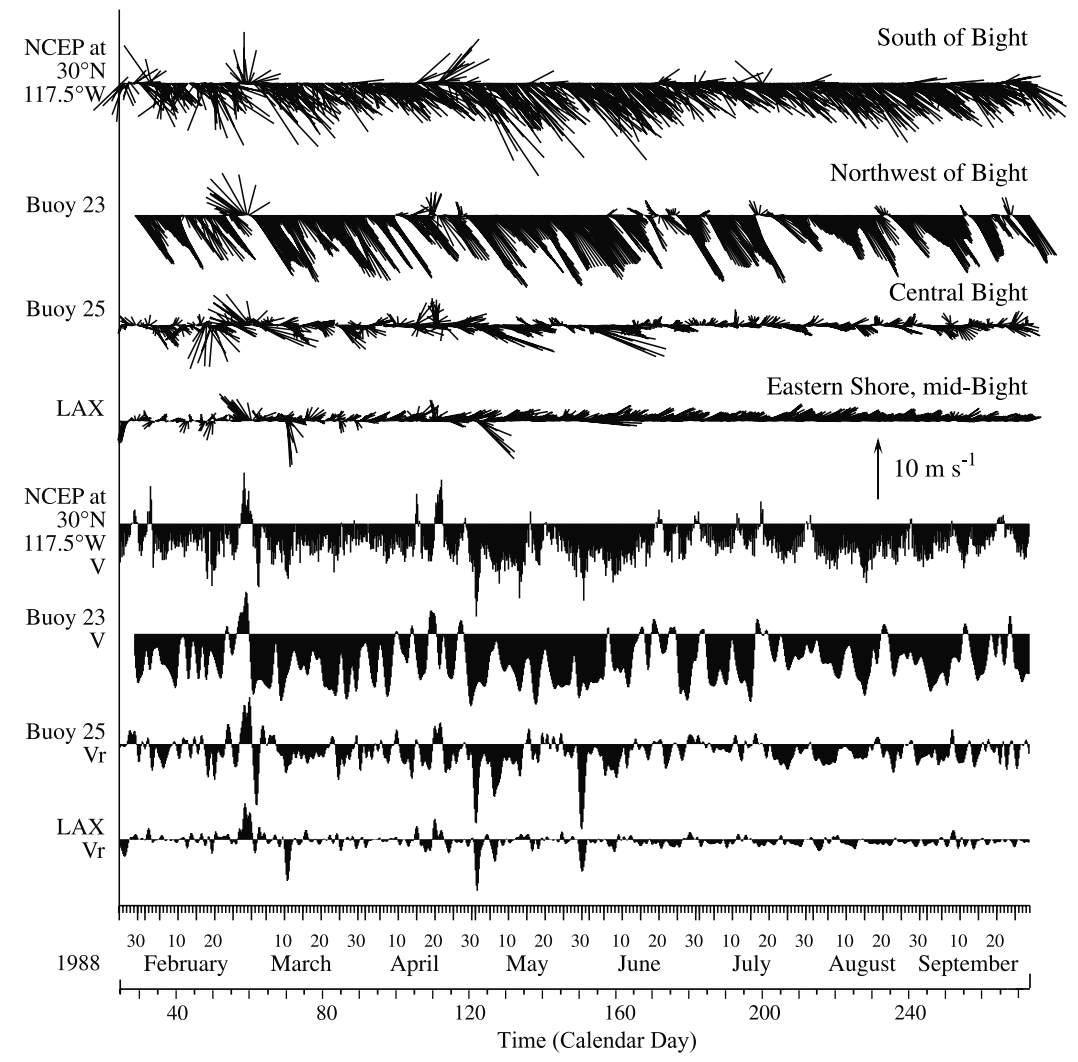

Figure 12. Time series of vector winds and alongshore winds (positive poleward) at latitude $30^{\circ} \mathrm{N}$ ("Reanalysis" winds), at buoy 23 and at buoy 25 as well as on the coast at LAX airport. Vector winds are shown in a north-south reference frame (positive northward and eastward). For the alongshore winds, Reanalysis winds, buoy 25, and LAX are shown in a local isobath coordinate system (positive poleward and onshore).

LAX are oriented predominantly onshore, particularly in summer when a strong sea breeze occurs. During spring, records at all locations are dominated by large, equatorward wind events: these events are large-scale, producing upwelling both inside and outside the bight [Hickey, 1992]. Both the amplitude and duration of these wind events generally decrease toward the coast. The strongest wind events over the nearshore basins of the central bight and SM Bay are equatorward, with the exception of two poleward events, one near February 28, and a weaker event near April 21. Comparison of the NCEP wind south of the bight with the other more local time series used in the analysis demonstrates that significant alongshore differences occur between the study site and the Baja California coast. The effect of these differences will be discussed in detail in section 4.5 where remote forcing of propagating disturbances is explicitly discussed.

[32] With the limited wind data available during this period, the best representation of wind stress forcing in the study region is not immediately obvious. No significant improvement in the analysis was obtained using, for example, a spatially averaged wind stress. The analysis will show that details of the local wind forcing are relatively unimportant because only a small amount of the variance is accounted for by local winds. With the exception of one upwelling event (not shown), data from LAX are less effective at predicting SM shelf currents than data from buoy 25 , suggesting that the LAX site may be partially sheltered. For consistency, data from buoy 25 are used to represent wind forcing in the entire central bight. Data from buoy 23 offshore of the bight are used to search for a possible relationship between local wind stress and largescale alongshore sea level slope.

\subsubsection{Alongshore Pressure Gradient}

[33] Several sea level stations are available in and near the bight and a number of different station pairs were examined to form estimates of the alongshore pressure gradient (APG). The final selection of stations used to drive the model in section 4.3 was based on the amount of velocity variance explained. Use of stations within the bight did not account for significant amounts of variance. The poor estimate obtained with these stations might be due to small-scale noise related to local topographic effects [Hickey, 1984]. Alternately, it might be due to datum jumps in the records [Lentz, 1993; Harms and Winant, 1994]. Significant variance was predicted using sea level differences from station pairs with Port San Luis, just north of the bight, Newport Beach, at midbight, and San Quintin, outside and equatorward of the bight. However, more variance was accounted for with some pairs of stations than with others. The greatest improvement in variance prediction generally occurred when the station outside and equatorward of the bight was included, particularly in summer. The next greatest improvement generally occurred with use of 

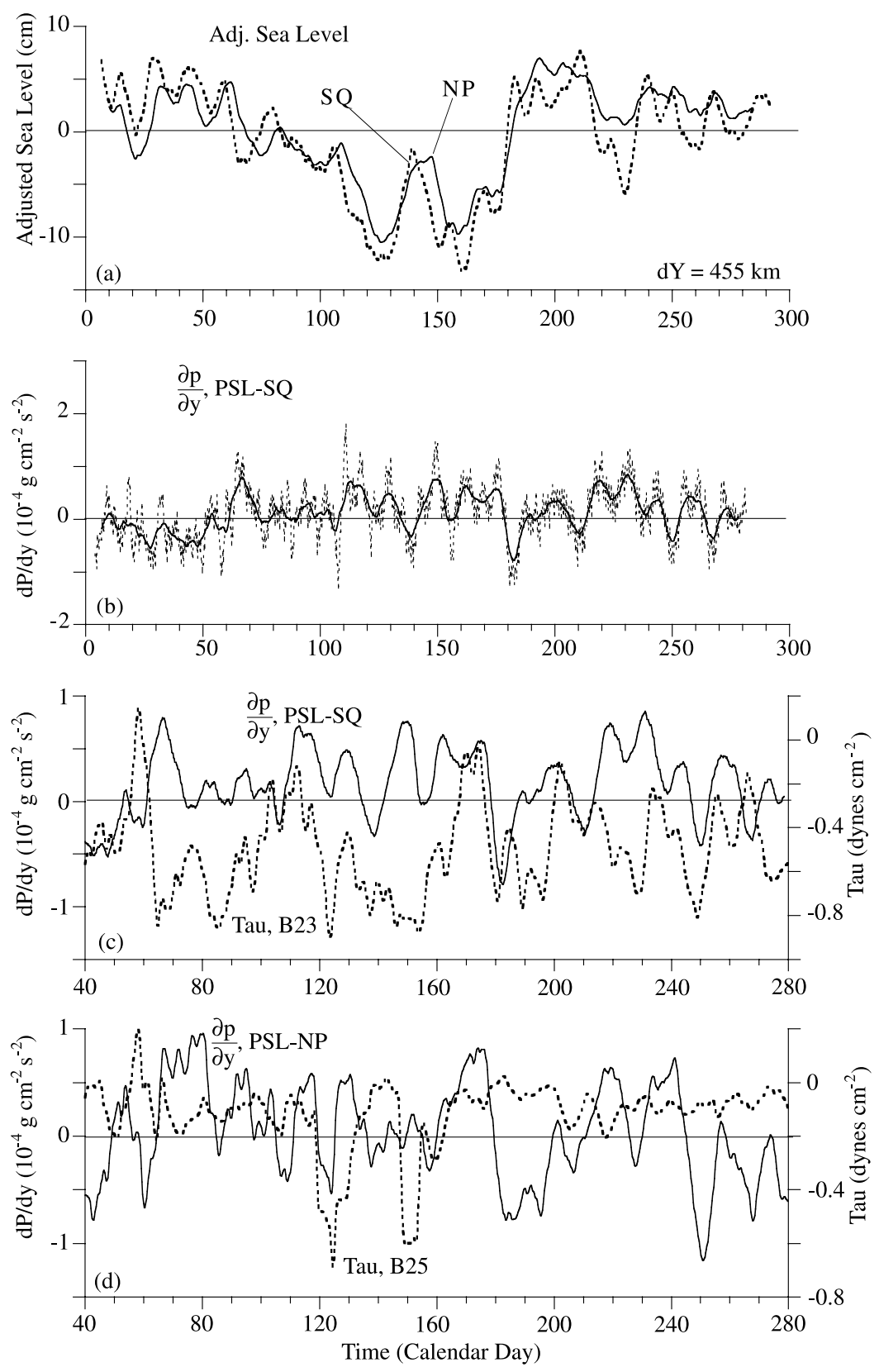

Figure 13. Comparison of (a) long-period adjusted sea level at Newport and San Quintin; (b) subtidal and long-period APG fluctuations; (c) long-period APG calculated between Port San Luis and San Quintin $(\mathrm{dy}=800 \mathrm{~km})$ and alongshore wind stress at buoy 23, located near Point Conception just offshore of the bight; and (d) long-period APG calculated between Port San Luis and Newport (dy $=344$ $\mathrm{km}$ ) and alongshore wind stress at buoy 25, located within SM Basin.

the station outside and just north of the bight. This station includes effects of the very strong coastal wind forcing just north of Point Conception, which might lead to an overestimate of APG for the SM region. On the other hand, the strong curl $\tau$-driven upwelling in the western end of the SB Channel [Wang, 1997; Oey, 1999] may lower sea level in the channel to a degree fortuitously represented by the sea level station farther north.

[34] Use of sea level difference estimated over the greatest alongcoast distance ("PSL-SQ", $800 \mathrm{~km}$ ) in most cases accounted for a higher percentage of variance than estimates over shorter distances such as Port San Luis to Newport
("PSL-NP", $344 \mathrm{~km}$ ) or Newport to San Quintin ("NPSQ", $455 \mathrm{~km}$ ). Results using any of these three time series are qualitatively similar: they all show the role of the APG in accelerating the flow in this region. The Port San Luis to San Quintin APG is used primarily in the following analysis; other APGs are used for comparison.

[35] Our data are not sufficient to accurately estimate the vertical structure of the APG. Dominant velocity fluctuations are quasi-barotropic; i.e., no direction reversals occur over the upper $200 \mathrm{~m}$ as shown by the vertical structure of the first EOF at the slope site (Figure 9). However, vertical shear in alongshore flow is significant even in the first EOF 
mode, and the second mode has large vertical shear with a spatially complex pattern. It seems reasonable to assume that the APG also has significant vertical structure, with an amplitude that decreases away from the sea surface. The vertical and cross-shore structure of the long-period fluctuations was best defined in an earlier data set [Hickey, 1992]. Guided by the structure shown in those data, we assume that the APG over the upper slope decreases linearly from the surface to $300 \mathrm{~m}$. This decay rate is consistent with both Hickey [1992] and the overall amplitude decay in the present data set (see Figure 10, where time series at 100 and $200 \mathrm{~m}$ are shown explicitly). On the SM shelf, where the structure of the first EOF mode shows no significant amplitude structure with depth, the APG is assumed constant to the bottom depth of about $30 \mathrm{~m}$.

[36] Alongshore pressure differences have significant short timescale variance that makes visual comparisons difficult and slightly reduces overall coherence for largerscale phenomena (Figure 13b). These fluctuations are filtered out by the dynamics of the linear model forced by the APG so that model velocities are generally long-period (10-25 days). However, to improve visual comparisons when discussing the APG, those data were smoothed to eliminate variability at shorter than 10 day periods, forming the "long-period" time series. The subtidal time series used to drive the model are compared with the long-period records in Figure 13b.

[37] In general, time series of adjusted sea level in this region indicate poleward signal propagation. For example, Newport lags San Quintin adjusted sea level consistently for the entire period (Figure 13a). Estimated poleward propagation speeds obtained from lagged correlations significant at the $95 \%$ level are $140 \mathrm{~cm} \mathrm{~s}^{-1}$ in spring and $260 \mathrm{~cm} \mathrm{~s}^{-1}$ in summer. Due to the propagating nature of the pressure field the APG was adjusted forward in time by 0.75 or $1.0 \mathrm{~d}$ when used to drive the circulation model in the SM Basin and inside the entrance to the SB Channel, respectively. The temporal advance was interpolated to these locations using the average adjusted sea level propagation speed.

[38] The APG is not significantly related to either local alongshore wind outside the bight (Figure 13c, B23; r = $-0.14,0.14$ in spring and summer, respectively) or to local wind near the SM-SP Basin (Figure 13d, B25; $r=-0.21$, -0.22 in spring and summer, respectively). As will be shown later, the large-scale APG largely represents the signature of freely propagating waves generated equatorward of the bight ("remotely") in both seasons.

\subsection{A Linear Model for Alongshore Velocity}

[39] In this section, alongshore wind stress and APG are used to drive a depth-averaged linear model of alongshore currents. This technique has been used successfully in regions where the coastline and bottom topography are reasonably simple [e.g., Lentz and Winant, 1986]. However, the region being considered here is not simple: the shelf widens and narrows, the shelf is indented by two submarine canyons, and the slope flow is blocked below $\sim 200 \mathrm{~m}$ by the Channel Islands and by ridges and islands that occur just $40 \mathrm{~km}$ offshore. Clearly in a region as complex as the central bight and within SM Bay linear dynamics cannot be expected to explain all processes at all space and timescales. However, our results will show that because of the domi- nance of large-scale, long-period fluctuations this approach is sufficient to at least delineate the dominant forcing mechanisms in this region.

[40] The alongshore momentum equation can be expressed as

$$
\frac{\partial \mathrm{v}}{\partial \mathrm{t}}+\mathrm{u} \frac{\partial \mathrm{v}}{\partial \mathrm{x}}+\mathrm{v} \frac{\partial \mathrm{v}}{\partial \mathrm{y}}+\mathrm{w} \frac{\partial \mathrm{v}}{\partial \mathrm{z}}+\mathrm{fu}=-\frac{1}{\rho} \frac{\partial \mathrm{p}}{\partial \mathrm{y}}-\frac{1}{\rho} \frac{\partial \tau^{y}}{\partial \mathrm{z}}
$$

where $\mathrm{u}, \mathrm{v}$ and $\mathrm{w}$ are the cross-shore, alongshore and vertical components of velocity (positive onshore, poleward and downward, respectively), $\mathrm{t}$ is time, $\rho$ is density, $\mathrm{p}$ is pressure, $f$ is the Coriolis parameter and $\tau^{\mathrm{y}}$ is the alongshore component of wind stress.

[41] Assuming linear dynamics to lowest order and averaging from surface to bottom over layer depth $\mathrm{H}$, then

$$
\frac{\partial \overline{\mathrm{v}}}{\partial \mathrm{t}}=\frac{\tau_{\mathrm{s}}^{\mathrm{y}}-\tau_{\mathrm{b}}^{\mathrm{y}}}{\rho \mathrm{H}}-\frac{1}{\rho} \frac{\overline{\partial \mathrm{p}}}{\partial \mathrm{y}}
$$

The depth-averaged Coriolis term is assumed negligible. While this assumption may be reasonable under some conditions near the coastal wall, its validity over the continental slope is less clear. In most applications including the present, attempts to calculate this term produce large numbers with poor correlations to other terms in (2). The relative success of the model at predicting the occurrence of extrema in the observed data suggests that the "real" Coriolis term is not dominant in the balance of momentum.

[42] If stress at the bottom of the layer is expressed as a linear function of depth-averaged velocity

$$
\tau_{\mathrm{b}}^{\mathrm{y}}=\rho \mathrm{r} \overline{\mathrm{v}}
$$

where $r$ is a resistance coefficient, (2) becomes

$$
\frac{\partial \overline{\mathrm{v}}}{\partial \mathrm{t}}=\frac{\tau_{\mathrm{s}}^{\mathrm{y}}}{\rho \mathrm{H}}-\frac{\mathrm{r} \overline{\mathrm{v}}}{\mathrm{H}}-\frac{1}{\rho} \frac{\overline{\partial p}}{\partial \mathrm{y}}
$$

Integrating (4), the depth-averaged alongshore velocity driven by alongshore wind stress and APG is given by

$$
\bar{v}=\bar{v}(0) e^{\frac{-\pi t}{H}}+\int_{0}^{t} \frac{\tau_{s}^{y}}{\rho H} e^{\frac{-r\left(t-t^{\prime}\right)}{H}} H_{d} t^{\prime}-\int_{0}^{t} \frac{1}{\rho} \frac{\overline{\partial p}}{\partial y} e^{\frac{-r\left(t-r^{\prime}\right)}{H}} d t^{\prime}
$$

Following the Lentz and Winant [1986] application in southern California, the resistance coefficient was set at $0.05 \mathrm{~cm} \mathrm{~s}^{-1}$ for the standard case. Since the model is linear, estimates can be made for wind stress and APG forcing alone or together. The APG-forced component provides an estimate of velocity variance resulting from disturbances generated equatorward of the local site that travel to the site as coastally trapped waves (CTWs) ("remote" forcing); the wind stress forced component provides an estimate of velocity variance forced by local wind stress at the site ("local" forcing).

[43] Goodness of fit was assessed using correlation coefficients or predicted variance. For typical spring and summer time series, $95 \%$ confidence levels are about 0.61 and $0.57 ; 90 \%$ levels are about 0.55 and 0.51 . Because of the long periods of the dominant fluctuations and corresponding 

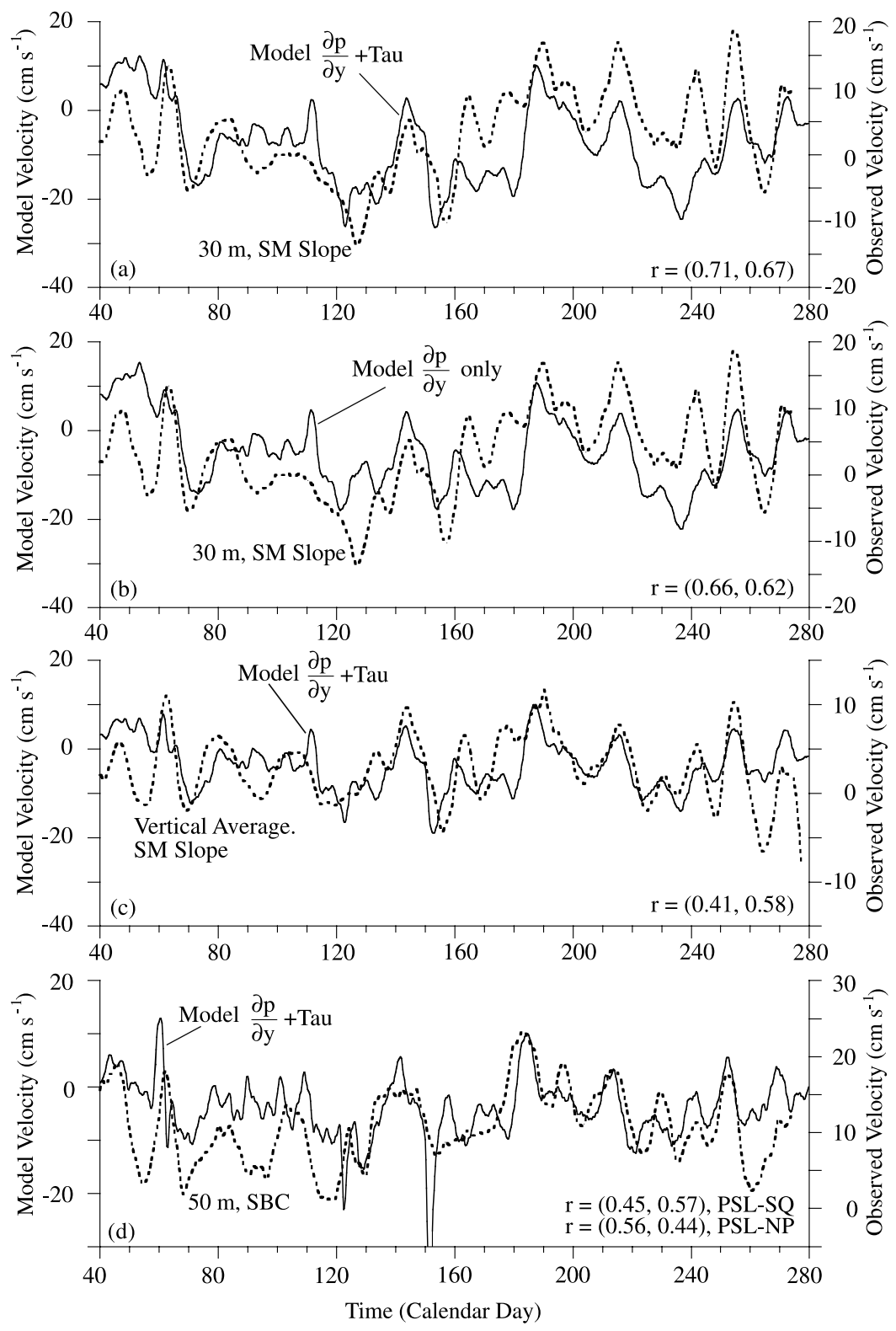

Figure 14. Comparison of observed long-period flow with flow predicted using a linear depth-averaged model. Correlations (i,j) are given for spring (i) and summer (j), respectively. (a) On the upper SM slope at $30 \mathrm{~m}$ (T7) in a $245 \mathrm{~m}$ bottom depth using both wind stress and APG forcing; model results have been advanced $2 \mathrm{~d}$ as discussed in the text; (b) on the upper SM slope at $30 \mathrm{~m}$ (T7) using only APG forcing; (c) depth-averaged flow over the SM slope; and (d) on the outer SB Channel shelf at $50 \mathrm{~m}$ (T12) in a $61 \mathrm{~m}$ bottom depth using both wind stress and APG forcing.

few degrees of freedom, the model fit is tested with its ability to recognize about 8 maxima in each season.

[44] Comparisons are shown with depth-averaged subtidal flow on both the inner shelf and the SM slope. Over the SM slope the correlation between model and observations at a single depth in the upper $30 \mathrm{~m}$ is significantly higher than for flow depth-averaged to $245 \mathrm{~m}$, particularly in spring (compare Figures 14a and 14c). This suggests that baroclinic, uncorrelated structure in the pressure field is significant at deeper depths and is not resolved by our simple linear vertical decay of the pressure gradient. To illustrate the ability of the model to predict extrema in the upper water column where our estimate of the pressure field is more accurate, comparisons are also shown at $30 \mathrm{~m}$ on the SM slope and at $50 \mathrm{~m}$ on the outer shelf in the SB Channel.

[45] One of the most striking results is that local windforced events are relatively infrequent at both slope (Figure 14 ) and shelf (Figure 15) sites. For example, over the SM slope only about $6 \%$ more long-period variance is accounted for when local wind forcing is included; compare the difference in fit between Figures 14a and 14b. Wind forcing on the slope makes significant contributions to the variance primarily during the two major equatorward flow events near days 125 and 160 . Shelf currents modeled with wind forcing alone account for about $25 \%$ of the variance in alongshore currents in spring and no significant 

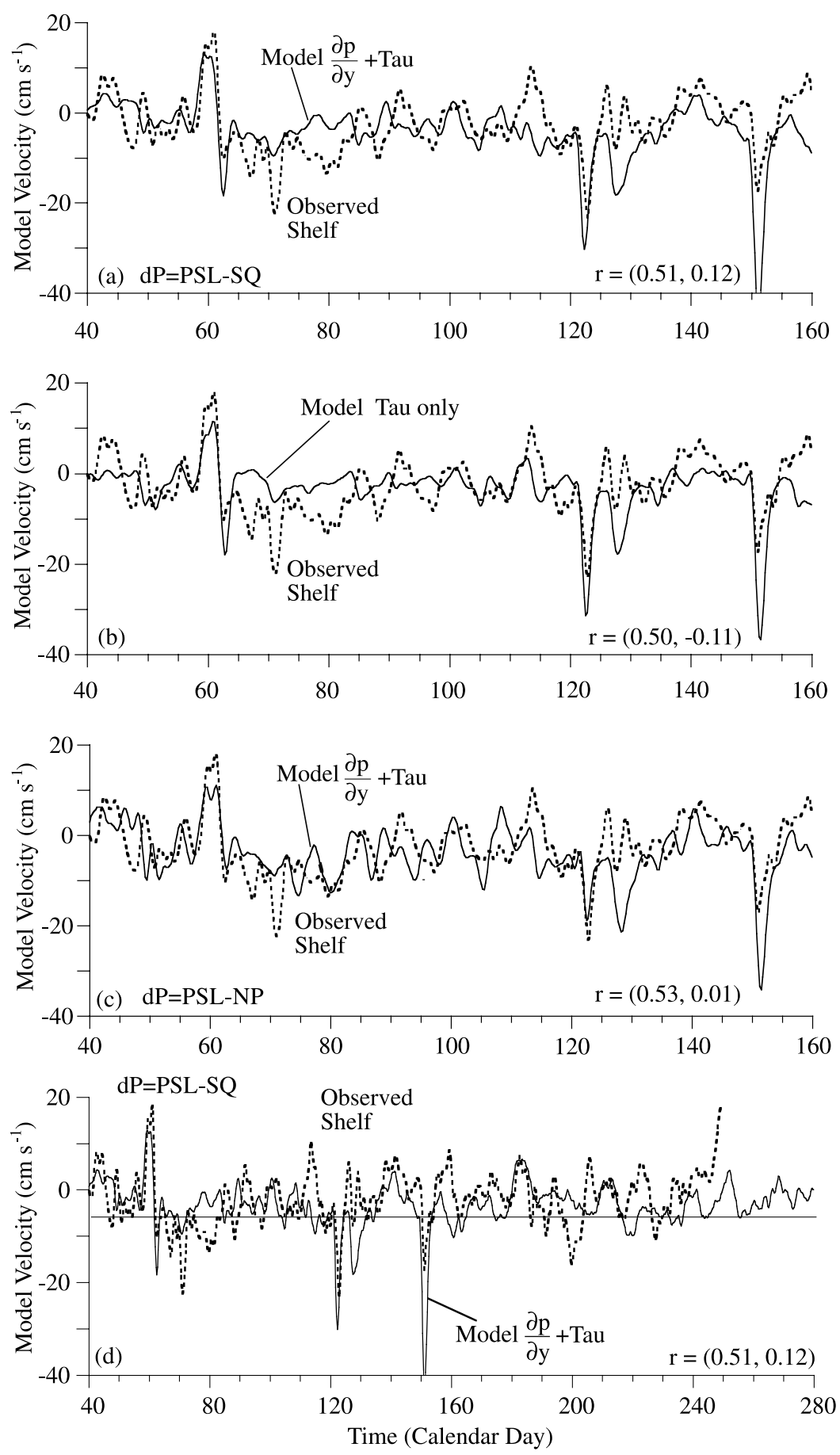

Figure 15. Comparison of observed depth-averaged flow on the SM shelf with flow predicted using a linear model depth averaged over $30 \mathrm{~m}$. Correlations (i,j) are given for spring (i) and summer (j), respectively. (a) Wind stress and APG forcing with the largest spatial-scale ( $200 \mathrm{~km})$ APG in spring; (b) wind stress forcing only in spring; (c) both wind stress and APG forcing using more local APG ( 344 $\mathrm{km})$ in spring; and (d) wind stress and APG forcing with the largest spatial-scale ( $\sim 800 \mathrm{~km})$ APG for both spring and summer.

fraction of the variance in summer (Figure 15b for spring). These results are consistent with the previously noted relationship between wind and EOF time series: significantly correlated in spring but not in summer (Figure 11). Between February 1 and May 3 five "significant" wind forced events, arbitrarily defined as events producing currents $>10 \mathrm{~cm} \mathrm{~s}^{-1}$, were observed on the shelf. Of these events, 5 were upwelling and 2 were downwelling. Associated timescales are 2-4 days, much shorter than those of the long-period fluctuations that dominate the variance at most sites in the region.

[46] The APG is clearly a dominant forcing mechanism over the SM slope in both spring and summer in the upper water column, with almost all observed extrema accounted 
for (Figures 14a and 14b, 44\% of the variance in spring, $38 \%$ in summer for APG alone; correlations are significant at the $90 \%$ level). The timing of extrema is estimated within $<2-4$ days. The APG also predicts a significant number of extrema in the depth-averaged flow, with all extrema accounted for in summer (Figure 14c). With both wind stress and APG included in the forcing up to $50 \%$ of the long-period alongshore current variance is accounted for on the SM slope in the upper water column in spring and $45 \%$ in summer (Figure 14a). About $35 \%$ of the variance on the outer shelf inside the mouth of the SB Channel is accounted for in both seasons (Figure 14d). The lower percent variance accounted for in the SB Channel may be due to the deeper measurement depth $(50 \mathrm{~m}$ versus $30 \mathrm{~m})$ at that site.

[47] In general, the model overpredicts amplitudes at individual sites in the upper water column (Figures 14a and $14 d$ ). This overprediction is to be expected since depthaveraged flow is less than flow at a single depth in the upper water column. However, the model also overpredicts the depth-averaged flow (Figure 14c). The overprediction is about a factor of three for model runs with the standard bottom friction coefficient of $0.05 \mathrm{~cm} \mathrm{~s}^{-1}$. A much better amplitude fit as well as higher correlations are obtained if a higher value of the bottom friction coefficient is used. We note that the fit is better than that obtained with a weaker APG forcing, which reduces model amplitudes but does not reproduce the structure of the fluctuations as well as increased drag. A model run using $\mathrm{r}=0.1 \mathrm{~cm} \mathrm{~s}^{-1}$ was used to generate the results shown in Figure 14c. The predicted variance is $28.9 \mathrm{~cm}^{2} \mathrm{~s}^{-2}$, only slightly greater than the observed variance of $20.4 \mathrm{~cm}^{2} \mathrm{~s}^{-2}$ (compared to $79.7 \mathrm{~cm}^{2}$ $\mathrm{s}^{-2}$ for the case with $\left.\mathrm{r}=0.05 \mathrm{~cm} \mathrm{~s}^{-1}\right)$. This seems counterintuitive: because velocity decreases dramatically toward the bottom over the upper slope, it might be expected that stress is already overestimated by our model, which approximates the stress as a linear function of the depth-averaged flow. We tentatively attribute this result to a loss of energy by wave scattering. In effect, the bottom friction coefficient provides a surrogate for energy drain due to scattering by the complex topography of the bight. Such scattering has been observed off the coast of Australia in a region of abrupt shelf widening [Wilkin and Chapman, 1990].

[48] The best fit between modeled and observed flow over the SM slope was obtained with the APG component of the model advanced by 2 days to account for the observed vertical lag shown in Figure 10. No timing adjustment was necessary at locations in shallower bottom depths such as the SB Channel shelf. Possible explanations for the lag are presented in section 6. Over the SM slope use of the larger-scale APG accounted for about four times as much variance as use of the more local-scale APG $(50 \%$ versus $14 \%$ in spring and $45 \%$ versus $11 \%$ in summer). On the outer shelf just inside the mouth of the SB Channel almost twice as much variance was accounted for in summer with the larger-scale APG. However, in spring more of the variance was accounted for by the local-scale APG.

[49] The model underpredicts poleward mean flow by several $\mathrm{cm} \mathrm{s}^{-1}$ at both individual sites in the upper water column and in the depth-averaged flow (Figure 14). At individual depths in the upper water column, the offset between the model and the observed flow grows by several $\mathrm{cm} \mathrm{s}^{-1}$ between spring and summer. The existence of both a long-term sea level slope [Reid and Mantyla, 1976] and a seasonally varying sea level slope [Enfield and Allen, 1980; Hickey and Pola, 1983] over the southern California/Baja coast is well established. Thus, although we could not expect to predict the mean flow with our forcing, from which the mean has been removed, we would expect to be able to capture the seasonal trend due to increasing poleward forcing from spring to summer. Further analysis of differences between adjusted sea level data using monthly means from 1980 to 1989 confirms that the expected seasonal cycle in slope is reproduced in long-term seasonal averages. However, during 1988, adjusted sea level differences using PSL do not have a seasonal cycle although a seasonal cycle is observed with other station pairs. The seasonal trend (May-September) for 1988 obtained using the demeaned adjusted sea level difference between an alternate station, Los Angeles, and San Quintin, results in a velocity trend of about $6 \mathrm{~cm} \mathrm{~s}^{-1}$. Addition of the longterm mean from Hickey and Pola [1983] produces a mean poleward velocity of $6 \mathrm{~cm} \mathrm{~s}^{-1}$. Thus the mean and trend of the "missing" poleward flow can both be accounted for. The reason for the missing seasonal trend at PSL was not determined. However, we note that large datum jumps in sea level records are not uncommon [Lentz, 1993; Harms and Winant, 1994].

[50] Neither local-scale nor large-scale APG accounts for a significant amount of variance on the inner shelf; compare Figures $15 \mathrm{a}$ and $15 \mathrm{c}$ with Figure 15b. Model results for summer account for less than $1 \%$ of the variance on the shelf (Figure 15d), considerably less than was accounted for on the slope (compare Figures $14 \mathrm{~d}$ and 15a). The section below presents an alternative explanation for some fraction of the observed current variance on the SM Bay shelf.

\subsection{Topographically Induced Flow in SM Bay}

[51] Much of the variability in SM Bay exhibits flow counter to that on the outer shelf and slope. This counterflow was captured in both seasons by the EOF analysis (Figure 8). Counterflow between shelf and slope was also observed in a fall-winter data set in 1985 [see Hickey, 1992, Figure 30] and is likely a ubiquitous feature of this region. The preceding section showed that a one-dimensional, linear model was only successful at predicting velocity variance on the SM shelf when fluctuations are driven by local wind stress, which tend to have a unidirectional flow pattern over the shelf. Indeed, counterflow within the bay is most apparent in summer when local wind-driven events rarely occur. The tendency for an inverse relationship in summer is shown explicitly in Figure 16a. To explore some three-dimensional effects of the complex topography, a nonlinear numerical model was applied to an idealized bay for a typical summer period (Figures 16b and 16c).

[52] The model bay is symmetrical, with a sloping bottom, a narrow continental slope north and south of the bay and a flat bottom $1000 \mathrm{~m}$ deep seaward of the slope (Figure 16b). The simplified shape is used to ensure that the effects of an alongslope flow on the adjacent shelf can be separated from more local topographic effects such as might be due to, for example, the two submarine canyons that indent the shelf break. The f-plane model has two isopycnal layers, the upper one of depth $10 \mathrm{~m}$, and a reduced gravity 

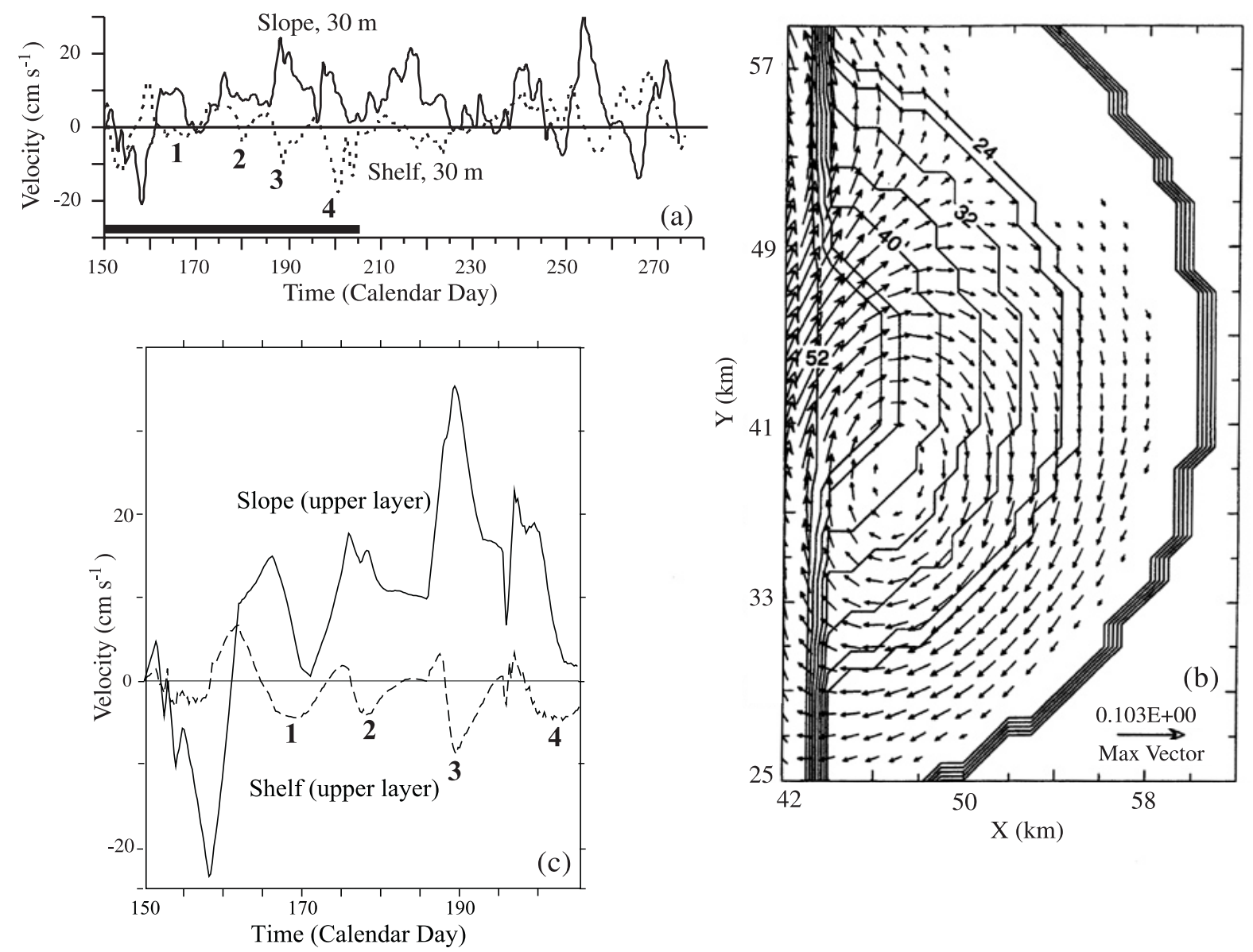

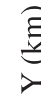

Figure 16. (a) Observed alongshore flow showing inverse relationship between flow on the shelf (T9) and the slope (T7). A solid line along the bottom axis indicates the period used for model comparison. (b) Bathymetry used in the SM Bay numerical model contoured every $4 \mathrm{~m}$; total model depth is $1000 \mathrm{~m}$ seaward of the slope. The rightmost contour is the coastline. Vector velocities in the upper layer on day 166.5 forced by observed flow over the slope are also shown. (c) Time series of upper layer shelf flow (dashed curve) simulated with an idealistic nonlinear, two layer, three-dimensional model driven by observed flow along the slope (solid curve) as also shown in Figure 16a.

between the layers of $0.1 \mathrm{~m} \mathrm{~s}^{-2}$. The model was forced by observed flow at $30 \mathrm{~m}$ over the SM slope for a $55 \mathrm{~d}$ period (Figures 16a and 16c). The model includes horizontal eddy viscosity of $10 \mathrm{~m}^{2} \mathrm{~s}^{-1}$ and viscosity between the two layers with an equivalent vertical eddy viscosity of $0.001 \mathrm{~m}^{2} \mathrm{~s}^{-1}$. A bottom Ekman layer is parameterized with depth $14 \mathrm{~m}$ and flux at 20 degrees to the right of the flow. Further details of the model are given by Allen [1996].

[53] The model domain is $62 \mathrm{~km}$ wide by $92 \mathrm{~km}$ long, with a grid spacing of $1 \mathrm{~km}$ that can just resolve the boundary layer due to horizontal viscosity, and a time step of $3 \mathrm{~s}$. The $1 \mathrm{~km}$ grid spacing is also sufficient to resolve the corners at the two ends of the bay, whose radii of curvature are about $1 \mathrm{~km}$. The boundary condition at the open ocean boundary is free slip. At the southern boundary an incoming barotropic wave is forced and a sponge is used to constrain the velocity parallel to shore. At the northern boundary, the pressure is separated into baroclinic and barotropic waves based on modal separation for the deep ocean and each wave is then propagated out of the domain at the appropriate Kelvin wave speed.
[54] The model illustrates that flow along the continental slope can produce counterflow within the adjacent semienclosed shelf (Figures 16b and 16c). Several equatorward events are reproduced on the shelf in the modeled time period (numbered 1-4 in the figures) although an exact prediction of observed currents in this complex domain was not our intent. Counterflow is generated within the bay by two mechanisms: nearshore reversals accompanying the initial change in slope flow, and flow separation at upstream boundaries. The initial flow reversal along the shelf edge and nearshore reinforces any preexisting counterflow or eddy in the bay. In general, flow within the bay, being weaker, is more easily reversed than flow over the slope and therefore reverses first. As a high-pressure disturbance associated with a pulse of poleward floss passes the mouth of the bay, the higher offshore pressure of the geostrophic alongslope flow accelerates flow into the bay to fill the bay. After the bay fills, it becomes part of the poleward throughflow. Over time, however, an anticyclonic or cyclonic eddy develops at the upstream end of the bay due to separation of the poleward or equatorward flow at 

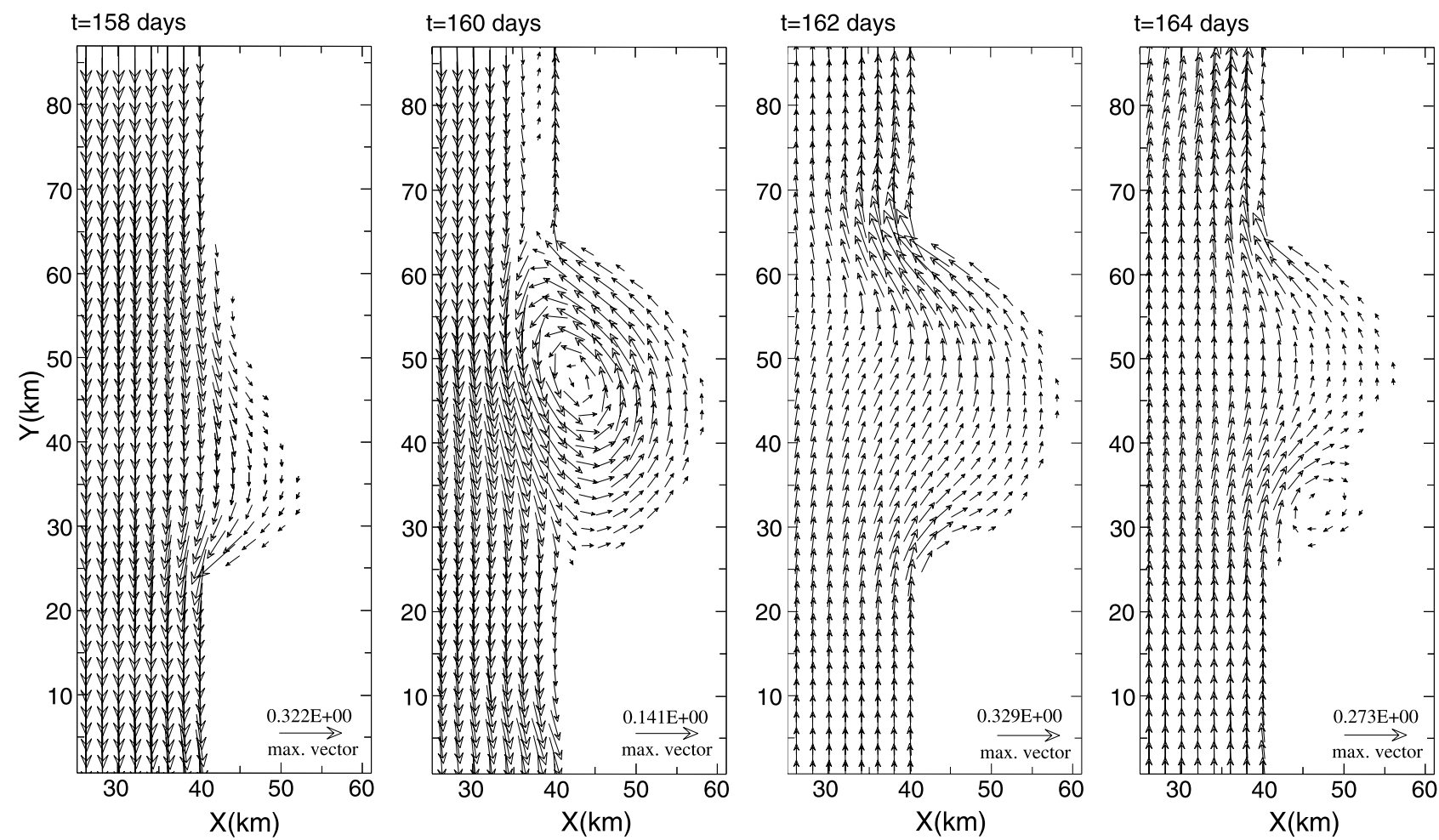

Figure 17. Model velocities in the upper layer showing the development of an eddy within SM Bay following a change in forcing over the slope. (a) Day 158, before the change of alongshore flow acceleration; (b) day 160, APG-driven flow reversal on the shelf; (c) day 162, the throughflow condition; and (d) day 164, anticyclonic eddy formation in the southern part of the bay. The fully developed anticyclonic eddy (day 166.5) is shown in Figure 16b.

the sharp corners. The eddy gradually fills the bay. The timescale for complete eddy development is $1.5-5$ days, with shorter times for stronger alongslope flows as shown in the numbered examples in Figure 16c. The vorticity of the eddy is generated from the no slip condition at the coast. The eddy dissipates by interfacial friction, with a timescale of about $0.5 \mathrm{~d}$. The lower layer spins down due to bottom friction. Until and unless a newly generated eddy fills the bay completely, circulation within the bay has a bidirectional pattern, similar to that of the observed seasonal mean circulation (see Figure 6).

[55] Plan view maps of surface layer vectors during a transition from a cyclonic to an anticyclonic pattern (day 158 to day 164) are shown in Figure 17. On day 158 when alongshore flow is equatorward, a weak cyclonic flow occurs in the northern end of the bay. When the APG reverses (day 160) the cyclonic tendency is reinforced and a cyclonic eddy fills the bay. By day 162 poleward flow occurs throughout the bay and over the slope. An anticyclonic eddy begins to form at the southern edge of the bay by day 164 . This eddy fills most of the bay by day 166.5 as shown in Figure 16b.

\subsection{Origin of Long-Period Velocity and APG Fluctuations}

[56] A complete analysis of the origin of the long-period fluctuations described in preceding sections is beyond the scope of this paper. However, results of the alongshore momentum analysis, which show that the dominant balance is between acceleration, APG and bottom stress are consistent with the dynamics of remotely forced propagating CTWs. The most common forcing of CTWs occurs as a result of gradients in alongshore wind stress along the coastline (e.g., for the Washington coast [Battisti and Hickey, 1984] and for the northern California coast [Chapman, 1987]). Indeed, alongshore winds near the coast are relatively weak within the bight and strengthen south of the bight [Hickey, 1979]. To assess the role of remote forcing by alongshore wind stress, lagged correlations were obtained between observed currents over the SM slope as well as adjusted sea level just north and just south of the bight and alongshore wind stress data at 2.5 degree intervals along the coast within and equatorward of the bight (Figure 18). Maximum correlation with currents, sea level and APG is obtained with wind stress several hundred kilometers equatorward of the bight rather than with wind stress local to the bight. Note that the increase of correlation between $32.5^{\circ} \mathrm{N}$ and $35^{\circ} \mathrm{N}$, rather than a reflection of an oceanic process, is likely a reflection of the large-scale nature of winds outside the bight in comparison with those within the bight (e.g., at $32.5^{\circ} \mathrm{N}$ ). With the exception of PSL sea level in summer, correlations are significant at the $90 \%$ level in both seasons. However, higher correlations are observed in summer than in fall and the region of maximum correlation is shifted farther equatorward in summer. The latitude of maximum correlation is near $30^{\circ} \mathrm{N}$ in spring and near $27.5^{\circ} \mathrm{N}$ in summer. The lag at maximum correlation with observed currents is consistent with the speed of a first-mode shelf 


\begin{tabular}{|c|c|c|c|c|c|c|}
\hline Spring & $35^{\circ} \mathrm{N}$ & $32.5^{\circ} \mathrm{N}$ & $30^{\circ} \mathrm{N}$ & $27.5^{\circ} \mathrm{N}$ & $25^{\circ} \mathrm{N}$ & $22.5^{\circ} \mathrm{N}$ \\
\hline $\mathrm{T} 7,30 \mathrm{~m}$ & $.50(4.25)$ & $.36(4.5)$ & $.64(4)^{*}$ & $.61(3.5)$ & $.42(5.5)$ & $.15(7.35)$ \\
\hline APG & $-.41(-5.25)$ & $-.17(-4.25)$ & $-.47(-5.25)$ & $-.39(-5.25)$ & $-.11(0)$ & $.39(9.5)$ \\
\hline SL,SQ & $.51(0)$ & $.28(0)$ & $.58(-.25)^{*}$ & $.53(1.75)$ & $.17(.5)$ & $-.42(9.25)$ \\
\hline SL,PSL & $.54(1)$ & $.38(1)$ & $65(1)^{*}$ & $.62(.5)^{*}$ & $.20(1)$ & $-.37(6.75)$ \\
\hline Summer & $35^{\circ} \mathrm{N}$ & $32.5^{\circ} \mathrm{N}$ & $30^{\circ} \mathrm{N}$ & $27.5^{\circ} \mathrm{N}$ & $25^{\circ} \mathrm{N}$ & $22.5^{\circ} \mathrm{N}$ \\
\hline $\mathrm{T} 7,30 \mathrm{~m}$ & $.36(2.25)$ & $.39(1)$ & $.48(4.75)$ & $.71(6)^{*}$ & $.54(5.5)$ & $.27(7.25)$ \\
\hline APG & $-.36(9.75$ & $-.30(-1.25)$ & $-.53(-.25)$ & $-.67(.75)^{*}$ & $-.25(.25)$ & $-.20(3)$ \\
\hline SL,SQ & $.26(0)$ & $.41(0)$ & $.60(0)$ & $.69(1)^{*}$ & $.45(1)$ & $.36(4)$ \\
\hline SL,PSL & $.45(1.75)$ & $.44(5)$ & $.46(4)$ & $.43(3.25)$ & $.55(9) *$ & $.53(9.5)$ \\
\hline
\end{tabular}

Figure 18. Maximum correlation and lag (in days) at maximum correlation between north-south ( alongshore) component of wind stress at selected latitudes and observed alongshore current at $30 \mathrm{~m}$ over the slope of SM Basin, adjusted sea level at Port San Luis (PSL, $35^{\circ} 10.6^{\prime} \mathrm{N}$ ) just north of the bight and San Quintin (SQ, $30^{\circ} 29^{\prime} \mathrm{N}$ ) outside and south of the bight, and the alongshore pressure gradient (APG) calculated between the two sea level stations. All data have been smoothed to represent only long periods (10-25 days) (see text). Results are given for spring and summer periods as defined in the text. Values of 0.55 are significant at the $90 \%$ level of confidence (starred values) and positive correlation indicates that wind stress leads the other variable in the data pair. Maximum correlation for each variable is shaded.

wave if the $\sim 2$ day lag of slope currents with respect to shelf edge currents shown in Figure 10 is removed from the total lag shown in the Figure 18.

[57] The results obtained by a consideration of lagged correlation with remote wind stress are similar to those obtained from analysis of correlations between adjusted sea level and the APG. In particular, correlations with adjusted sea level are consistently higher with the station equatorward of the bight ( $\mathrm{r}=-0.76,-0.54$ in spring, summer, where the $90 \%$ level of significance is $\sim 0.55$ ) than with the station poleward of the bight $(\mathrm{r}=-0.61,-0.17$ in spring, summer), suggesting that the large-scale APG is more influenced by adjusted sea level equatorward of the bight in both seasons. The station poleward of the bight, taken as representative of sea level within and just north of the SB Channel, has much more influence on the APG in spring than in summer.

\section{Origin of Near-Surface Water Property Fluctuations}

[58] Poleward and equatorward advection of large-scale warm and cold tongues of water (respectively) dominate sequences of satellite images of sea surface temperature in the SC Bight [Hickey, 1992; Harms, 1996]. Mean ocean temperature is much colder in the northern half of the bight due to coastal upwelling at and near Point Conception and much warmer in the southern half of the bight due to seasonal poleward advection of southern water [Hickey, 1979, 1992]. The mean surface alongshore temperature difference between Point Conception and SM Basin can exceed $6^{\circ} \mathrm{C}$, particularly from spring to early fall [Harms, 1996]. Tongues of cold water enter the SB Channel at its west end and move eastward along its southern boundary; tongues of warm water emanate from equatorward of the bight, passing through the bight on its shoreward side and entering the SB Channel on its northern side. A map of SST variance in spring displays two regions of maximum variance: one in the SB Channel near Point Conception, a second south of the SB Channel, with a minimum between the two regions [Atkinson et al., 1986]. This spatial structure is consistent with two sources of temperature variance in the bight: one with a southern origin and one with a northern origin. In the following section we will attempt to show that a significant portion of observed long-period temperature variance in the upper water column is due to lateral advection of large-scale spatial gradients by the large-scale, long-period flow field.

[59] In general, vertical mixing, heating and cooling, lateral advection, vertical advection associated with crossstream geostrophic balance and coastal upwelling can each be important contributors to near-surface temperature variance in the coastal ocean. Both heating and advection have been shown to be important to the vertically averaged heat balance in the SB Channel [Auad et al., 1999]. At shorter than seasonal scales, vertical heat flux has maximum variance in wind-driven frequency bands rather than the lower frequencies addressed here. Below, we demonstrate that 1) lateral advection by the large-scale, long-period velocity fluctuations discussed in the previous section is an important contributor to temperature fluctuations in the upper water column; and 2) that local upwelling contributes to temperature variance near the coastal wall of the SM shelf.

[60] First, consider the heat equation for regions outside the influence of the coastal wall; i.e., farther than one 

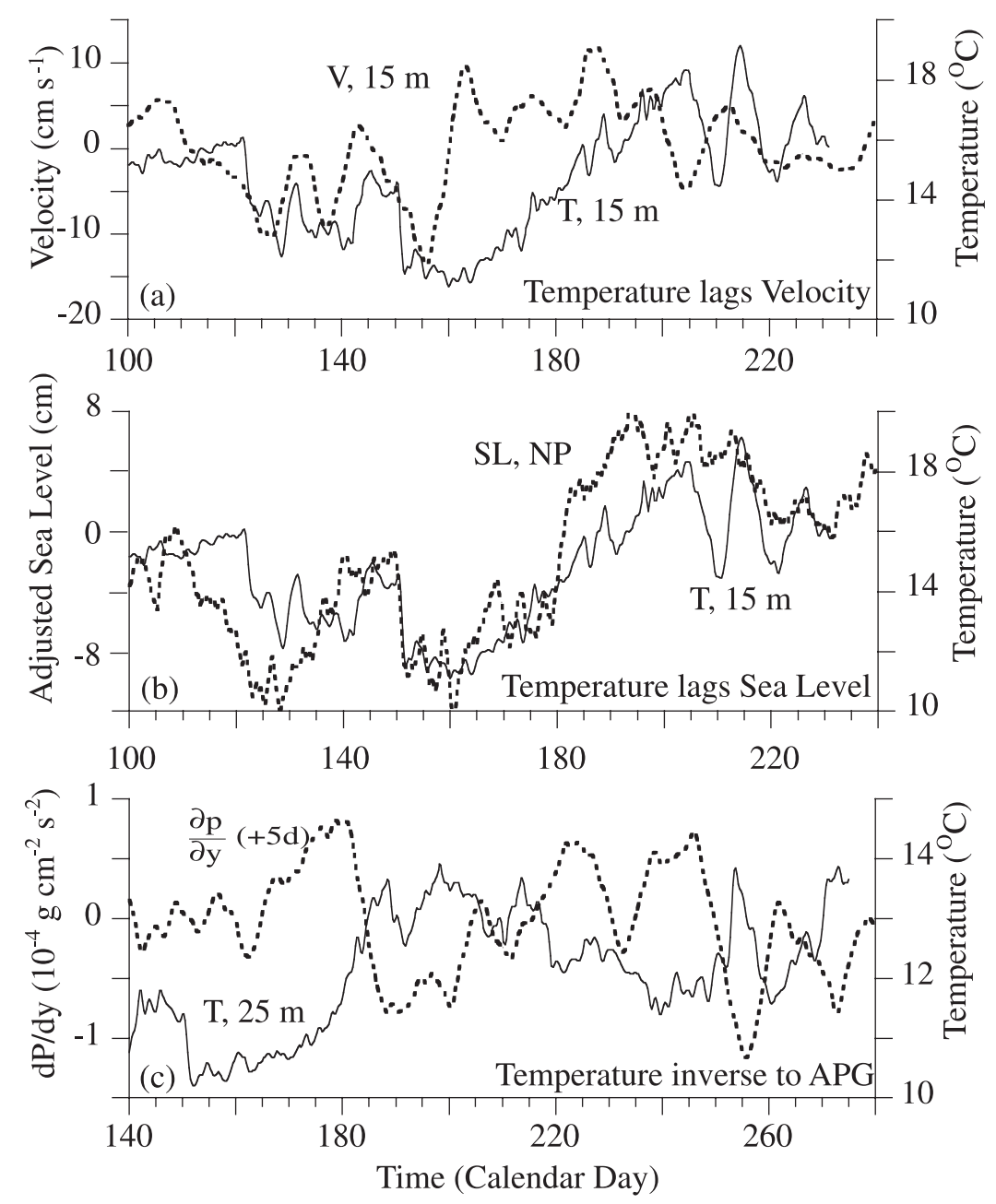

Figure 19. Comparison of (a) subtidal temperature and long-period alongshore velocity on the SM slope at $15 \mathrm{~m}$; (b) subtidal temperature and long-period adjusted sea level at Newport on the SM slope at $15 \mathrm{~m}$; and (c) long-period APG (PSL-NP) advanced by 5 days and subtidal temperature on the SM Bay outer shelf.

Rossby Radius from the coast. We assume that solar heating is not dominant for the timescales considered. Cross-shore advection is neglected because both cross-shore velocities and cross-shore temperature gradients are typically weaker than alongshore gradients (see Hickey [1992, Figures 6 and 8] for velocity fields and Hickey [1992, Figures 2 and 15] for surface temperature fields). With these simplifications, the heat balance can be described by

$$
\frac{\partial \mathrm{T}}{\partial \mathrm{t}}=-\mathrm{v} \frac{\partial \mathrm{T}}{\partial \mathrm{y}}-\mathrm{w} \frac{\partial \mathrm{T}}{\partial \mathrm{z}}
$$

[61] If the time rate of change of temperature is caused primarily by vertical advection due to geostrophic tilting we would expect alongshore velocity to be roughly in phase with temperature because maximum (minimum) temperature and maximum poleward (equatorward) flow occur at the same time if the flow is geostrophically balanced. However, temperature time series at and above $30 \mathrm{~m}$ show that rather than being in phase with alongshore flow, temperature frequently lags flow (see example for location T7; Figure 19a). Temperature fluctuations also tend to lag sea level fluctuations (Figure 19b). Thus, even though temperature profiles indicate that observed temperature fluctuations could be consistent with vertical excursions of 20-50 m such as might reasonably occur to geostrophically balance changes in the alongshore flow, phase relationships are not consistent with such a relationship. Isopycnal tilting undoubtedly occurs to geostrophically balance velocity shear over the upper $200 \mathrm{~m}$ but the velocity EOF illustrates that much of the vertical shear, and hence geostrophic adjustment, occurs below $40 \mathrm{~m}$.

[62] If lateral advection is dominant in (6) and if the temperature gradient is essentially constant we would expect temperature to lag alongshore velocity as observed (Figure 19a). In addition, temperature is significantly correlated with APG during some periods, with maximum correlation when APG leads temperature by about 5 days (e.g., $r=-0.65$ from day 180 to the record end, where $\mathrm{r}=$ 0.59 for $90 \%$ significance; Figure 19c). Correlations are particularly strong in summer. The observed phase relationship is consistent with the hypothesis that the APG accelerates the flow and that this flow advects heat laterally along the coast producing the observed temporal changes 

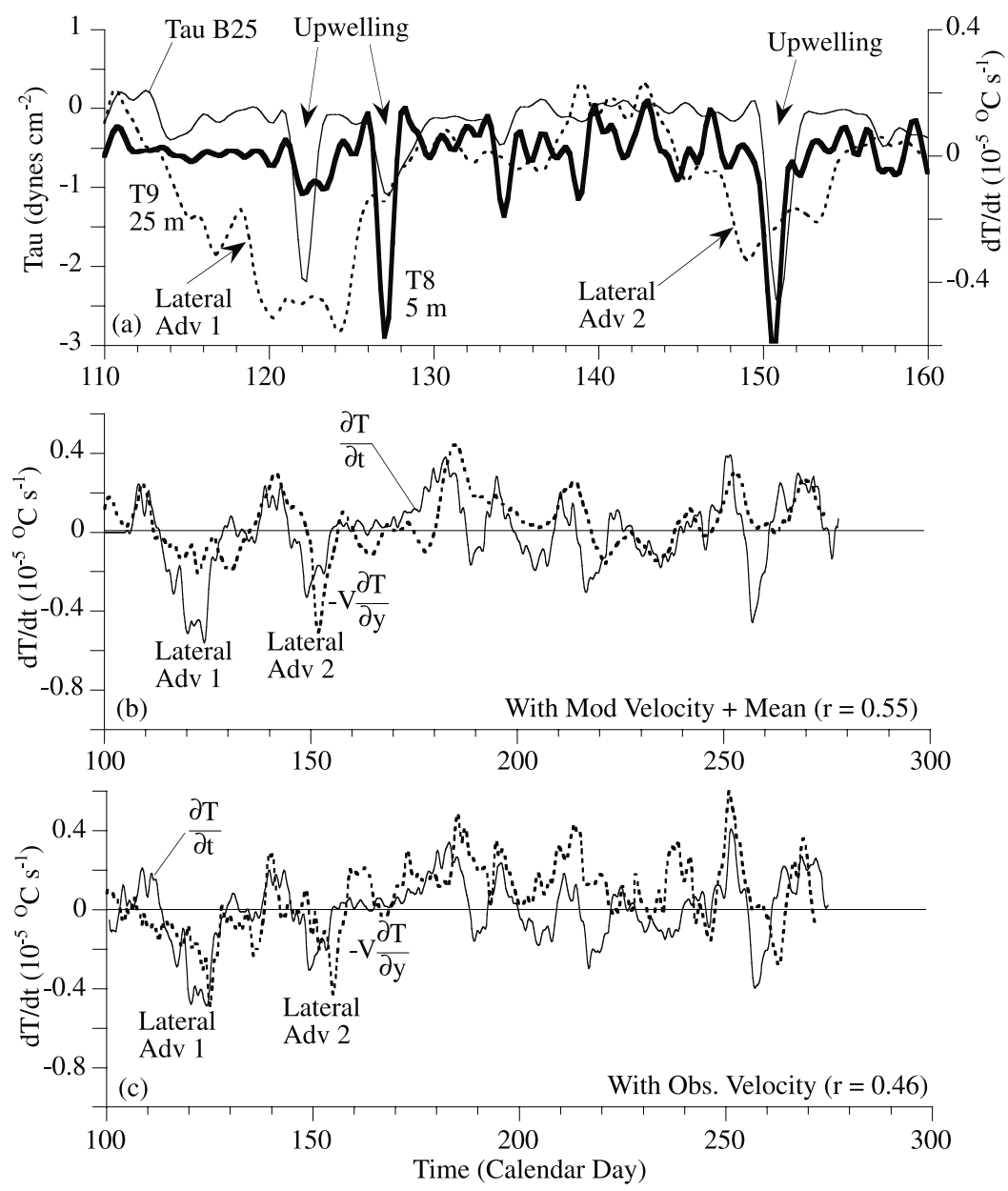

Figure 20. (a) Comparison of alongshore wind stress at buoy 25 and time rate of change of long-period temperature at a site within the Rossby Radius of deformation from the coast $(<5 \mathrm{~km}$, T8, heavy solid line) and at a site outside the Rossby Radius ( $\sim 11 \mathrm{~km}, \mathrm{~T} 9$, dashed line). Strong local upwelling events, with associated rapid changes in temperature, as well as advective events, with associated slower temperature changes are noted. (b) Time rate of change of long-period temperature on the outer shelf (T9, $25 \mathrm{~m}$ ) and alongshore advective contributions to the time rate of change. Advective events noted in Figure 20a are also noted here for comparison. Velocity was derived from the linear wind stress-APG model depth averaged over $111 \mathrm{~m}$ and driven by the largest spatial-scale APG. The alongshore temperature gradient was held constant. (c) As in Figure 20b using observed subtidal velocity over the SM slope (T7) adjusted by $2 \mathrm{~d}$ to account for the shelf to slope lag as discussed in the text.

in temperature. To test this relationship explicitly, the time rate of change of near-surface temperature at a site on the outer shelf was compared with alongshore advective changes estimated using a constant spatial gradient $\left(2^{\circ} \mathrm{C}\right.$ per $100 \mathrm{~km}$ ) derived from seasonal mean data by Harms [1996]. Velocity was taken from the large-scale model for slope bottom depths or from the upper slope observations adjusted by $2 \mathrm{~d}$ to account for the observed shelf to slope lag. Reasonable results using the model required the addition of a poleward mean flow to the modeled flow. The mean was taken from the mean difference between the model and the observations $\left(9 \mathrm{~cm} \mathrm{~s}^{-1}\right)$. Results indicate that advective contributions to the variance are similar in magnitude to the observed changes and are also significantly correlated to the observed changes $(r=0.55$ for the modeled flow, 0.44 for the observed flow, where $r=0.44$ for the $95 \%$ level of significance; Figures $20 \mathrm{~b}$ and 20c).
The advective model for near-surface temperature changes accounts for the majority of events remarkably well considering the simplicity of the model: acceleration driven by pressure differences over a distance of $800 \mathrm{~km}$ and a constant alongshore temperature gradient. Maximum equatorward transport of cold water occurs during periods when both wind stress and APG forcing are in the same direction (see events labeled Adv 1 and Adv 2; forcing during those periods is shown in Figure 14).

[63] Temperature changes near the coastal wall have distinctly different characteristics from those farther offshore discussed above. In particular, at shallow depths at stations located within one internal Rossby Radius of the coast upwelling driven by local winds is clearly apparent in several isolated events (e.g., T8, $5 \mathrm{~m}$ at $4 \mathrm{~km}$ from the coastal wall; Figure 20a). During these events the time rate of change of temperature is exactly in phase with along- 
shore wind stress as expected for upwelling dynamics near a coastal wall [Brink et al., 1987]. The rapid temperature decrease contrasts with the more gradual decrease observed farther offshore where, as discussed above, fluctuations appear to be consistent with lateral advection (e.g., T9, 25 $\mathrm{m}$ at $11 \mathrm{~km}$ from the coastal wall; Figure 20a).

\section{Discussion and Summary}

[64] Dominant velocity and temperature fluctuations along the outer shelf and slope in the central SC Bight occur at relatively long periods (10-25 days) and exceed the central bight in scale. The analysis in this paper covers a spring-fall period; similar fluctuations were observed in fallwinter 1985 and in spring-fall 1986 [Hickey, 1992]. A linear depth-averaged model forced by local alongshore wind stress and large-scale APG was used to show that these fluctuations are forced primarily by long-period sea level disturbances that propagate poleward along the coast through the bight, accelerating currents as they pass a local area. These fluctuations account for at least $40 \%$ of the velocity variance over the shelf edge and slope in both spring and summer. The pressure disturbances have a very large along-coast scale $(>800 \mathrm{~km})$ and originate primarily equatorward of the bight. Only during winter [from Hickey, 1992] and spring (this data set) are currents within the central bight forced directly by the local wind stress. Winddriven events occur infrequently $(\sim 3-5$ events each in winter and spring), accounting for less than $25 \%$ of the alongshore velocity variance. Wind-driven velocity fluctuations have comparatively short timescales ( $<10$ days). In this regard the central bight region differs from both the northern bight (the SB Channel), where local upwelling continues throughout the summer at its western end [Harms and Winant, 1998], and also from regions north of Point Conception that are more strongly wind forced and less bathymetrically complex [Hickey, 1989, 1998; Winant et al., 1987].

[65] Several lines of evidence suggest that the long-period disturbances are the signature of low-mode CTWs. For example, in both the present analysis and in previous work [Hickey, 1992; Auad and Hendershott, 1997] sea level data show that the disturbances travel at speeds consistent with low-mode CTWs (140-260 $\left.\mathrm{cm} \mathrm{s}^{-1}\right)$. In the Hickey [1992] data set the spatial structure of the disturbances was coastally trapped from summer to winter, consistent with the derived structure of the lowest-mode CTW for this region [Auad and Hendershott, 1997]. In the spatially comprehensive velocity data set of Hickey [1992] velocity data were used to show that the disturbances slow as they enter the central bight and that some portion of the signal is transmitted westward south of the Channel Islands. In both the Hickey [1992] data set and the present data set velocity variance had a subsurface maximum near $100 \mathrm{~m}$. Longperiod sea level fluctuations have been observed off the coast of Baja California just south of San Diego [Christensen and Rodriguez, 1979]. Data in a study of the large-scale properties of coastal sea level along the coast of North America suggest that long-period fluctuations may be present from about $25^{\circ} \mathrm{N}$ to San Francisco [see Spillane et al., 1987, Figure 3]. Christensen et al. [1983] show that sea level events along the Mexican mainland propagate pole- ward as CTWs into the Gulf of California, but not beyond it. Thus, generation of the long-period fluctuations likely occurs well south of the bight but north of the entrance to the Gulf of California, as our data also suggest.

[66] The data demonstrate that currents over the slope of SM Basin and the APG are significantly correlated to winds near $27.5^{\circ}-30^{\circ} \mathrm{N}$ rather than to local winds, suggesting that remote wind forcing plays a role in the generation of the long-period CTWs. The region of maximum generation occurs farther south in summer than in spring. Lentz and Winant [1986] also showed that fluctuations in the APG near San Diego $\left(\sim 32^{\circ} \mathrm{N}\right)$ were more strongly related to winds to the south $\left(\sim 30^{\circ} \mathrm{N}\right)$ than to local winds. A recent study in the same region has demonstrated a relationship between temperature on the shelf and alongshore winds near $26^{\circ}-30^{\circ} \mathrm{N}$ (J. M. Pringle, Remotely forced nearshore upwelling in southern California, submitted to Journal of Geophysical Research, 2002). It is also possible that fluctuations are generated by alongshore gradients in curl $\tau$ as has been suggested by numerical model studies for seasonal scales [Oey, 1999]. Curl $\tau$ has also been invoked as contributing to circulation patterns in the SB Channel near Point Conception, a major bend in the coastline that alters local wind fields [Wang, 1997]. The role of along-coast gradients in $\tau$ or curl $\tau$ cannot be examined further without more detailed threedimensional modeling forced by a wind data set that resolves both alongshore and across shore gradients in the nearshore features in the wind field.

[67] Large outer shelf to slope phase lags (2-4 days between stations separated by as little as $5-10 \mathrm{~km}$ ) were documented by Hickey [1992] for two other periods as well as in the present data set. The offshore phase propagation is consistent with frictional modification of CTWs [Brink, 1982] and was captured by our linear model, which predicted a lag of about 2 days between $60 \mathrm{~m}$ and $245 \mathrm{~m}$ bottom depths. In the present data set we demonstrate an additional characteristic of the fluctuations; i.e., significant vertical phase propagation (a $\sim 2$ day lag between $100 \mathrm{~m}$ and $200 \mathrm{~m}$ ), such that disturbances occur earlier deeper in the water column. The APG is closer in phase with the deeper fluctuations. Thus both the upper water column velocity fluctuations and the depth-averaged flow, which tends to be weighted by the stronger near-surface fluctuations, lag the fluctuations predicted by our simple APG driven model by as much as 2 days. A possible explanation for both vertical and horizontal lags is that the incident velocity fluctuations are scattered into a number of wave modes by the complex topography of the bight. As in the case shown in a region of shelf widening off the coast of Australia [Wilkin and Chapman, 1990], modes can interact either constructively or destructively to give a variety of phase and spatial patterns at different sites.

[68] Our results show that the contribution of equatorward energy (remote forcing) increases between spring and fall and that the likely generation region is a few hundred kilometers more distant in summer than in spring. The previous finding that velocity fluctuations were basin-wide in spring but slope-trapped in summer to fall and winter [Hickey, 1992] is also consistent with a more remote initiation site later in the season than in spring. A possible interpretation is that in summer and fall disturbances travel a 


\section{SC Bight Long Period Circulation}

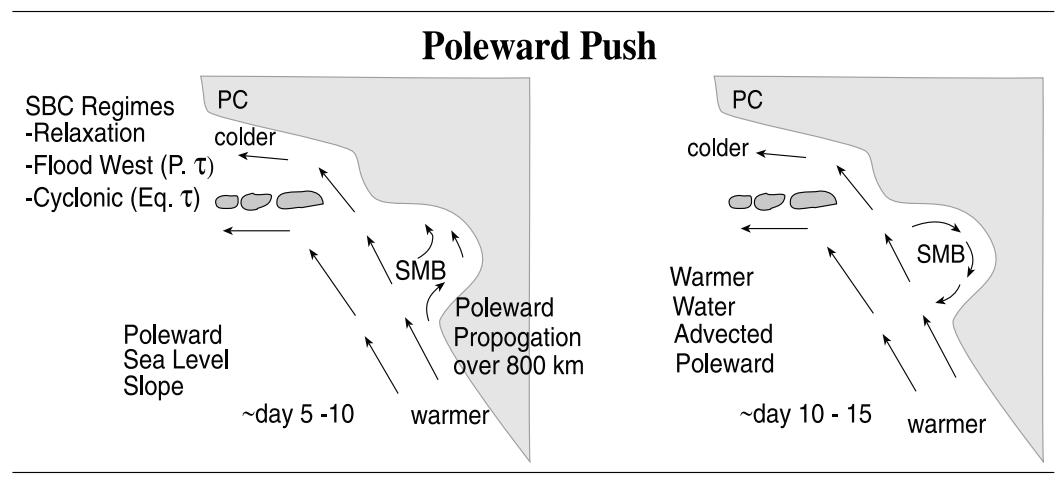

Equatorward Push
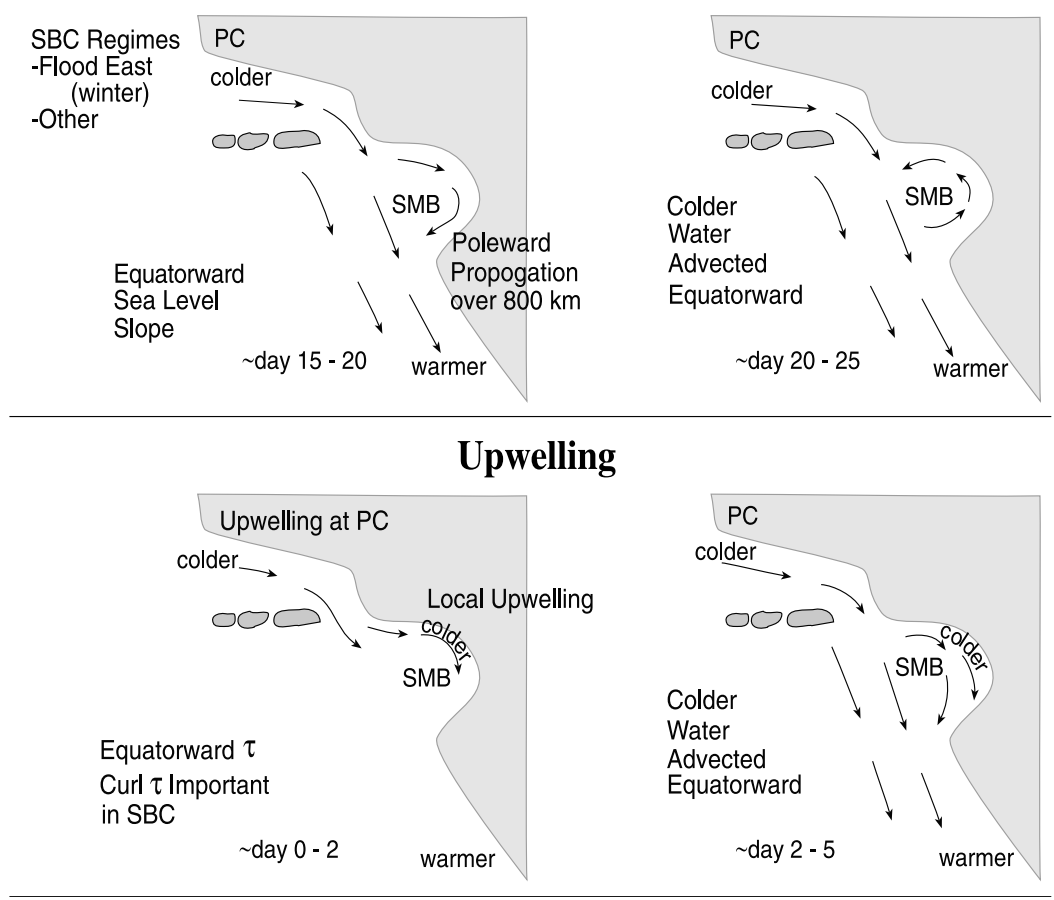

Figure 21. Schematic showing processes affecting long-period (10-25 days) circulation and water properties in the central SC Bight. "Regimes" in the SB Channel refer to flow regimes described by Harms and Winant [1998]. A temporal sequence from a poleward to an equatorward "push" is illustrated, with patterns drawn every 5 days. For a poleward or equatorward push, panels on the left describe the circulation after the APG forcing has reversed the flow; panels on the right describe the circulation after a topographically driven eddy has filled SM Bay.

greater distance from the point of origin and are therefore observed in the central bight region with the spatial structure of freely propagating CTWs because they are outside the forcing region; in spring, the central SC Bight may be partly within the forcing region so that pure freely propagating CTWs are less in evidence.

[69] The same large-scale remote forcing that is responsible for much of the velocity variance in the central bight can also control much of the velocity variance over the adjacent shelf (SM Bay), although the dynamics within the bay likely differ from those over the slope. In particular, event-scale counterflow within the bay, a ubiquitous feature of bay data sets, appears to be driven by slope processes. Results from an idealistic, nonlinear, three-dimensional model show that as a high-pressure pulse passes the semi- enclosed shelf, water is pushed into the bay initially as part of a throughflow. An eddy forms due to flow separation near the upstream corner of the bay, gradually filling the bay and producing counterflow on the shoreward side of the bay. Similar flow separations due to APG changes have been observed and modeled for the Baie des Chaleurs [Gan et al., 1997]. The development of an eddy in the SB Channel due to flow separation near Point Conception has been modeled by Oey [1999]. The effects of nonlinearity and coastline geometry on such topographically forced eddies have been investigated by Signell and Geyer [1991] in an application with unsteady tidal flows.

[70] The very large-scale, long-period remote forcing also appears to be responsible for a significant fraction of the upper water column temperature variance within the region, 
the majority of which is also large-scale and occurs at long periods. Both phase analysis and explicit estimates of temperature changes suggest that long-period temperature fluctuations in and above the pycnocline within the central $\mathrm{SC}$ Bight can occur as a result of lateral advection by the long-period flow events rather than solely by geostrophic adjustment (i.e., vertical advection) of isopycnal surfaces. Lateral advection has also been shown to be important to total heat transport through the SB Channel just north of the SM Basin [Auad et al., 1999]. Advective events are not simply "CODE relaxation" events, which bring warmer water poleward when equatorward alongshore winds relax and the mean poleward APG force (negative APG) is more effective [Send et al., 1987]. In the central SC Bight, fluctuating propagating APGs produce currents that transport heat in both directions. Particularly strong equatorward transport of cold water occurs during periods when both wind stress and APG forcing are in the same direction. In very nearshore regions, temperature changes due to local upwelling are distinguished from advective changes by their much faster time rate of change and their in phase correlation with local alongshore wind stress.

[71] Results from this analysis have been used to develop a conceptual model for circulation in SM Bay and over the adjacent offshore channels (Figure 21). Processes are linked to current patterns that have been identified for the SB Channel [Harms and Winant, 1998]. For example, conditions "Flood East" and "Flood West" are associated with unidirectional surface flow in the channel, respectively, generally observed when winds are in the same direction as the APG forcing. The "Cyclonic" pattern in the SB Channel is associated with strong upwelling winds and a strong poleward APG force. "Local upwelling" in the SB Channel refers to upwelling primarily near Point Conception. For simplicity, we have grouped patterns into those in which the APG forcing is either poleward or equatorward ("Poleward or Equatorward Push") and those in which local wind in the SM Basin is large and equatorward ("Upwelling"). Thus, a poleward push through the SM Basin may occur contemporaneously with a Relaxation, Cyclonic or Flood West pattern in the SB Channel. An equatorward push may occur as part of a Flood East pattern (primarily in winter) or may appear simply as a period of reduction in the prevailing poleward flow (Other). Current patterns are drawn for $\sim 5$ days after the beginning of such a $\sim 20$ day "push" and $\sim 5$ days later when counterflow has developed within SM Bay. A poleward push brings warmer water, an equatorward push, colder water into SM Basin and bay primarily via lateral advection (with a several day lag between APG forcing and temperature). Upwelling provides colder water in the bay near the coast (via local upwelling) as well as over the basins (primarily via lateral advection from the SB Channel).

[72] Although the percent of total observed variance in along-basin flow accounted for by the linear, large-scale model on the outer shelf and over the channels never exceeds roughly half the variance, the relatively good phase agreement suggests that the majority of long-period fluctuations are at least partially accounted for with linear dynamics forced by the APG (primary) and local alongbasin wind stress (secondary, and only in spring). The percent may be much higher at individual sites, where EOF analysis showed as much as $65-90 \%$ of the variance was related to large-scale processes. However, at most sites local features such as canyons or coastal headlands produce smaller-scale "noise" in the response to the forcing that reduces overall site-to-site correlation. Some of the unexplained variance is likely due to other forcing mechanisms; e.g., some evidence of wind forcing is observed in the 4-6 day frequency band. In spite of substantial effort, analysis of higher-frequency and shorter-scale fluctuations in this data set proved elusive. A high-resolution three-dimensional model driven by appropriate forcing mechanisms may help elucidate variance occurring at the shorter space scales and timescales, whether because of a complex response to the large-scale forcing identified in this paper or to other forcing mechanisms.

[73] Acknowledgments. Data were collected as one component of the CaBS (California Basin Study) Department of Energy program (contract DE-FG05-85ER 60333 to B. Hickey). Support for the analysis was provided by the Minerals Management Services (contract 14-35-01-96CT-30819 to B. Hickey), by the National Science Foundation (OCE 9618186 to B. Hickey and J. Klinck), and by the Office of Naval Research (contract N00014-00-1-0093 to L. Thomson and B. Hickey). The threedimensional modeling was performed with support from an NSERC research grant to S. Allen. E. Dobbins was supported by an ONR Fellowship. We would like to thank S. Geier for assistance in the statistical analysis, N. Kachel for assistance in data display and D. Ripley for successfully deploying and recovering the moored array. C. Harris processed the ADCP data. We are especially indebted to those who shared their data with us including R. Flick, N. Bond, and H. Mojfeld. Finally, we would like to thank J. Pringle for sharing his recent results and for reminding us that remote wind forcing may be important in this region.

\section{References}

Allen, S. E., Topographically generated, subinertial flows within a finite length canyon, J. Phys. Oceanogr., 26, 1608-1632, 1996.

Atkinson, L. P., K. H. Brink, R. E. Davis, B. H. Jones, T. Paluszkiewicz, and D. W. Stuart, Mesoscale hydrographic variability in the vicinity of Point Conception and Arguello during April-May 1983: The OPUS 1983 Experiment, J. Geophys. Res., 91, 12,899-12,918, 1986.

Auad, G., and M. C. Hendershott, The low frequency transport in the Santa Barbara Channel: Description and forcing, Cont. Shelf Res., 17, 779802,1997

Auad, G., M. C. Hendershott, and C. D. Winant, Mass and heat balances in the Santa Barbara Channel: Estimation, description and forcing, Prog. Oceanogr., 43, 11-155, 1999.

Battisti, D. S., and B. M. Hickey, Application of remote wind forced coastal trapped wave theory to the Oregon and Washington coasts, J. Phys. Oceanogr., 14, 887-903, 1984.

Bray, N. A., A. A. Keyes, and W. M. L. Morawitz, The California Current System in the Southern California Bight and the Santa Barbara Channel, J. Geophys. Res., 104, 7695-7714, 1997.

Brink, K. H., The effect of bottom friction on low-frequency coastal trapped waves, J. Phys. Oceanogr., 12, 127-133, 1982.

Brink, K. H., and R. D. Muench, Circulation in the Point Conception-Santa Barbara Channel region, J. Geophys. Res., 91, 877-895, 1986.

Brink, K. H., D. C. Chapman, and G. R. Halliwell, A stochastic model for wind-driven currents over the continental shelf, J. Geophys. Res., 92, 1783-1797, 1987.

Chapman, D. C., Application of wind-forced, long, coastal-trapped wave theory along the California coast, J. Geophys. Res., 92, 1798-1816, 1987.

Christensen, N., Jr., and N. Rodriguez, A study of sea level variations and currents off Baja California, J. Phys. Oceanogr., 9, 631-638, 1979.

Christensen, N., Jr., R. De La Paz, and G. Gutierrez, A study of sub-inertial waves off the west coast of Mexico, Deep Sea Res., Part A, 30, 835-850, 1983.

Davis, R. E., Predictability of sea surface temperature and sea level pressure anomalies of the North Pacific, J. Phys. Oceanogr., 6, 249-266, 1976.

Enfield, D. B., and J. S. Allen, On the structure and dynamics of monthly sea level anomalies along the Pacific coast of North and South America, J. Phys. Oceanogr., 25, 1867-1889, 1980.

Gan, J. P., R. G. Ingram, and R. J. Greatbach, On the unsteady separation/ intrusion of the Gaspe current and variability in Baie des Chaleurs, J. Geophys. Res., 102, 15,567-15,581, 1997. 
Harms, S., Circulation induced by winds and pressure gradients in the Santa Barbara Channel, Ph.D. diss., 138 pp., Univ. of Calif., San Diego, 1996. Harms, S., and C. D. Winant, Synthetic subsurface pressure derived from bottom pressure and tide gauge observations, J. Atmos. Oceanic. Technol., 11, 1625-1637, 1994.

Harms, S., and C. D. Winant, Characteristic patterns of the circulation in the Santa Barbara Channel, J. Geophys. Res., 103, 3041-3065, 1998.

Hickey, B. M., The California Current system-Hypotheses and facts, Prog. Oceanogr., 8, 191-279, 1979.

Hickey, B. M., The fluctuating longshore pressure gradient on the Pacific Northwest shelf: A dynamical analysis, J. Phys. Oceanogr., 14, 276-293, 1984.

Hickey, B. M., Patterns and processes of circulation over the shelf and slope, in Coastal Oceanography of Washington and Oregon, edited by M. L. Landry and B. M. Hickey, pp. 41-115, Elsevier Sci., New York, 1989.

Hickey, B. M., Circulation over the Santa Monica-San Pedro Basin and shelf, Prog. Oceanogr., 30, 37-115, 1992.

Hickey, B. M., Physical oceanography, in Marine Ecology of the Southern California Bight, edited by M. D. Daley, D. J. Reish, and J. W. Anderson, pp. 19-70, Univ. of Calif. Press, Berkeley, 1993.

Hickey, B. M., Response of a narrow submarine canyon to strong wind forcing, J. Phys. Oceanogr., 27, 698-726, 1997.

Hickey, B. M., Coastal Oceanography of western North America from the tip of Baja California to Vancouver Island, in The Sea, vol. 11, edited by A. R. Robinson and K. H. Brink, pp. 345-393, John Wiley, New York, 1998.

Hickey, B. M., and N. E. Pola, The seasonal alongshore pressure gradient on the west coast of the United States, J. Geophys. Res., 88, 7623-7633, 1983.

Kalnay, E., et al., The NCEP/NCAR 40-year reanalysis project, Bull. Am. Meteorol. Soc., 77, 437-471, 1996.

Koopmans, L. H., The Spectral Analysis of Time Series, 366 pp., Academic, San Diego, Calif., 1974.

Kundu, P. K., and J. S. Allen, Modal decomposition of the velocity field near the Oregon coast, J. Phys. Oceanogr., 5, 683-704, 1976.

Large, W. G., and S. Pond, Open ocean momentum flux measurements in moderate to strong winds, J. Phys. Oceanogr., 11, 324-336, 1981.

Lentz, S. J., The accuracy of tide gauge measurements at subtidal frequencies, J. Atmos. Oceanic Technol., 10, 238-245, 1993.

Lentz, S. J., and C. D. Winant, Subinertial currents on the southern California shelf, J. Phys. Oceanogr., 16, 1737-1750, 1986.

Lynn, R. S., and J. J. Simpson, The California current system-The seasonal variability of its physical characteristics, J. Geophys. Res., 92, $12,947-12,966,1987$.
Lynn, R. S., and J. J. Simpson, The flow of the undercurrent over the continental borderland off southern California, J. Geophys. Res., 95, 12,995-13,009, 1990.

Oey, L.-Y., A forcing mechanism for the poleward flow off the southern California coast, J. Geophys. Res., 104, 13,529-13,539, 1999.

Reid, J. L., and A. W. Mantyla, The effect of geostrophic flow upon coastal sea level elevations in the northern Pacific Ocean, J. Geophys. Res., 81, 3100-3110, 1976.

Send, U., R. C. Beardsley, and C. D. Winant, Relaxation from upwelling in the Coastal Ocean Dynamics Experiment, J. Geophys. Res., 92, $1683-$ 1698, 1987.

Signell, R. P., and W. R. Geyer, Transient eddy formation around headlands, J. Geophys. Res., 96, 2561-2575, 1991.

Spillane, M. C., D. B. Enfield, and J. S. Allen, Intraseasonal oscillations in sea level along the west coast of the Americas, J. Phys. Oceanogr., 17, 313-325, 1987.

Tibby, R. B., The water masses of the west coast of North America, J. Mar. Res., 4, 113-121, 1941.

Wang, D.-P., Effects of small-scale wind on coastal upwelling with application to Point Conception, J. Geophys. Res., 102, 15,555-15,566, 1997.

Wilkin, J. L., and D. C. Chapman, Scattering of coastal-trapped waves by irregularities in coastline and topography, J. Phys. Oceanogr., 20, 396421, 1990

Winant, C. D., Longshore coherence on the southern California shelf during the summer, J. Phys. Oceanogr., 13, 54-64, 1983.

Winant, C. D., and A. W. Bratkovich, Temperature and currents on the southern California shelf: A description of the variability, J. Phys. Oceanogr., 11, 71-86, 1981 .

Winant, C. D., and C. E. Dorman, Seasonal patterns of surface wind stress over the Southern California Bight, J. Geophys. Res., 102, 5641-5654, 1997.

Winant, C. D., R. C. Beardsley, and R. E. Davis, Moored wind, temperature, and current observations made during the Coastal Ocean Dynamics Experiments 1 and 2 over the northern California continental shelf and upper slope, J. Geophys. Res., 92, 1569-1604, 1987.

S. E. Allen, Department of Earth and Ocean Sciences, University of British Columbia, Vancouver, B. C., Canada V6T 1 Z4.

E. L. Dobbins, Joint Institute for the Study of the Atmosphere and Ocean, University of Washington, Box 357941, Seattle, WA 98195, USA.

B. M. Hickey, School of Oceanography, University of Washington, Box 355351, Seattle, WA 98195, USA. (hickey@ocean.washington.edu) 